\title{
High-resolution vertical profile measurements for carbon dioxide and water vapour concentrations within and above crop canopies
}

4 Patrizia Ney - Alexander Graf

6 Received: date / Accepted: date

\begin{abstract}
We present a portable elevator-based facility for measuring $\mathrm{CO}_{2}$, water vapour, temperature and wind-speed profiles between the soil surface and the atmospheric surface layer above crop canopies. The end of a tube connected to a closed-path gas analyzer is continuously moved up and down over the profile range (in our case, approximately $2 \mathrm{~m}$ ) while concentrations are logged at a frequency of $20 \mathrm{~s}^{-1}$. Using campaign measurements in winter wheat, winter barley and a catch crop mixture (spring 2015 to autumn 2016) during different stages of crop development and different times of the day, we demonstrate a simple approach to correct for time lags, and the resulting profiles of 30-min mean mole fractions of $\mathrm{CO}_{2}$ and $\mathrm{H}_{2} \mathrm{O}$ over height increments of $0.025 \mathrm{~m}$. The profiles clearly show the effects of soil respiration and photosynthetic carbon assimilation, varying both during the diurnal cycle and during the growing season. Profiles of temperature and wind speed are based on a ventilated finewire thermocouple and a hot-wire anemometer, respectively. Measurements over bare soil and a short plant canopy were analyzed in the framework of Monin-Obukhov similarity theory to check the validity of the measurements and raw-data-processing approach. Derived fluxes of $\mathrm{CO}_{2}$, latent and sensible heat and momentum show good agreement with eddycovariance measurements.
\end{abstract}

Keywords Elevator - Evapotranspiration - Monin-Obukhov similarity theory · Respiration

\section{Introduction}

Surface-layer gradients or profiles of temperature, wind speed, humidity and trace gases have traditionally been used to determine the near-surface turbulent fluxes

P. Ney

Agrosphere (IBG-3), Institute of Bio- and Geosciences, Jülich Research Centre, 52425 Jülich, Germany

Tel.: +49-2461-6196848

E-mail: p.ney@fz-juelich.de 
of momentum, sensible and latent heat, before the eddy-covariance method became feasible on a large scale. Today, they are used to determine storage terms and advection (Aubinet et al., 2005; Montagnani et al., 2009), inform or validate models (Sogachev et al., 2005; Haverd et al., 2011), partition vertically displaced sinks and sources (Raupach, 1989; Leuning, 2000; Santos et al., 2011) and characterize microclimatic conditions in plant canopies. As with other flux determination methods, such as the relaxed-eddy-accumulation (REA) method (Businger and Oncley, 1990; Fotiadi et al., 2005a,b) and the disjunct-eddy-covariance (DEC) method (Rinne et al., 2001; Baghi et al., 2012), profile measurements are also used in conditions, or for scalars, not suitable for eddy-covariance measurements, e.g., because rapid-response sensors are unavailable. For sensor-based measurements, the costs increase proportionally with the number of measurement levels, and care must be taken to calibrate sensors against each other since any systematic deviation will affect the apparent profile. For trace gases and humidity, this can be avoided by multiplexer systems, and for temperature and partly also humidity, distributed temperature sensing has recently been suggested (Thomas et al., 2012; Euser et al., 2014). Another means of obtaining data from an arbitrary number of measurement heights consists of sounding, i.e. moving the same sensor or trace-gas analyzer inlet vertically. This is frequently done on a large scale with radiosondes, tethersondes and aircraft (Lothon et al., 2014), but has received comparatively little attention in surface-layer (?) or canopy studies.

Accurate micrometeorological measurements in low and dense plant stands are particularly challenging. Instruments must not affect plant activity or structure, and dense canopies lack the large volumes of air to which most conventional instruments are adapted. Only few studies have been done with elevator systems for measuring vertical profiles, and most of them were preconfigured to stop at a finite number of levels. Noone et al. (2013) used an elevator system at a $300-\mathrm{m}$ high research tower to obtain $\mathrm{H}_{2} \mathrm{O}$ and $\mathrm{CO}_{2}$ mixing ratios every few tens of metres, with a sounding time of $9 \mathrm{~min}$ for one ascent/descent. Mayer et al. (2009, 2011) tested an existing service elevator on a 99-m tower to measure profiles of temperature, relative humidity and mixing ratios of $\mathrm{CO}_{2}, \mathrm{H}_{2} \mathrm{O}$ and $\mathrm{O}_{3}$ in continuous mode, moving up and down once every $10 \mathrm{~min}$. A smaller elevator was used by Jäggi et al. (2006) to measures ozone profiles with a total vertical distance of $1.5 \mathrm{~m}$, which moved alternately to seven levels and remained at each for at least 100 s. Drüe (1996) designed a 1.2-m high elevator, which moves at 30-s intervals to a specified height to measure temperature and radiation fluxes for $20 \mathrm{~s}$.

Gradients of water vapour and $\mathrm{CO}_{2}$ concentrations within and above different plant populations have mostly been obtained using multiport systems, which are controlled by solenoid valves, sampling air sequentially at five to eight levels, taking from 1 min (Al-Saidi et al., 2009; Xu et al., 1999) to 10-20 min (Ahonen et al., 1997; Brooks et al., 1997; Buchmann and Ehleringer, 1998) or 30 min (Leuning, 2000; Miyata et al., 2000) for one cycle (profile).

Here, we introduce a technique to obtain vertical profiles of $\mathrm{CO}_{2}$ and $\mathrm{H}_{2} \mathrm{O}$ (as mole fractions $\chi_{\mathrm{CO}_{2}}$ and $\chi_{\mathrm{H}_{2} \mathrm{O}}$ ), as well as temperature and wind speed within and above crop canopies and bare soil, as an amendment to existing eddy-covariance measurements. An elevator continuously moves up and down (taking approximately $36 \mathrm{~s}$ for one ascent/descent) between the soil surface and $2.1 \mathrm{~m}$ a.g.l. with an ascent speed around $0.06 \mathrm{~m} \mathrm{~s}^{-1}$, collecting about 25 profiles each in upward and downward mode over $30 \mathrm{~min}$ at a logging frequency of $20 \mathrm{~s}^{-1}$. The system was 
installed and operated on selected measurement days to act as a mobile campaign solution and as a prototype for a long-term installation, which requires additional protection against heavy rain and windy conditions. While the actual vertical and temporal resolution can be configured during data processing, we here mostly present 30-min mean profiles of 0.025-m thick layer averages as a basis for checking the plausibility of the measurement and raw-data-processing approach. For those measurements that were made over bare soil and short canopies, flux-profile relationships are well established and a particularly rigid plausibility test can be performed by comparing fluxes derived from these profiles to eddy-covariance measurements. Such a comparison is given below.

\section{Methods}

\subsection{Test site}

The tests were carried out at the TERENO research site Selhausen (ICOS site code DE-RuS). The test site is situated in the southern part of the Lower Rhine Embayment in the river Rur catchment $\left(50^{\circ} 52^{\prime} 09^{\prime \prime} \mathrm{N}, 06^{\circ} 27^{\prime} 01\right.$ 'E, $104.5 \mathrm{~m}$ a.s.1., Fig.1) in Germany.

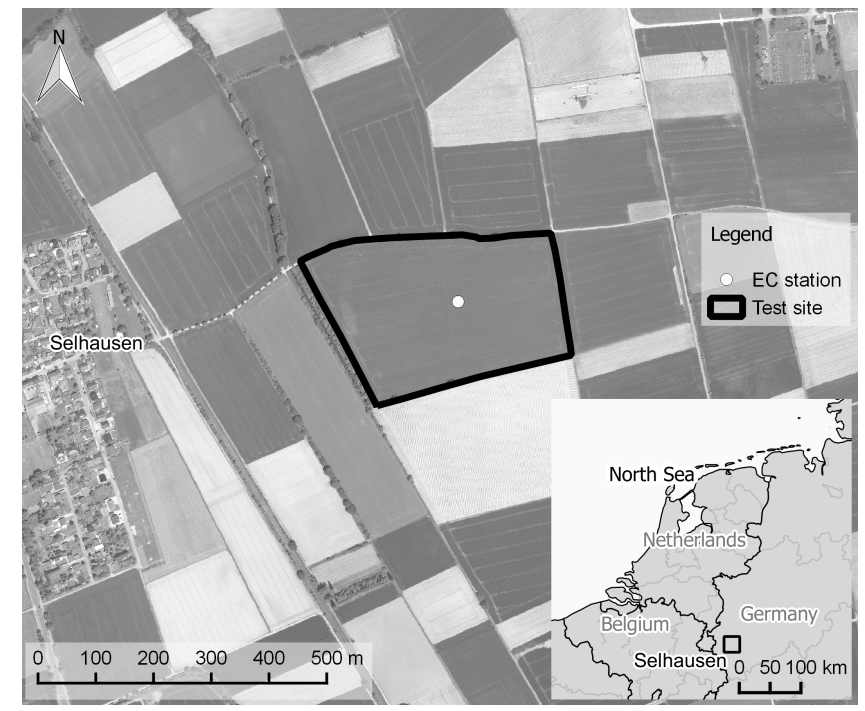

Fig. 1 Overview of the test site Selhausen.

The device was placed and operated in a test field with a size of 9.8 ha, cultivated with a rotation of crops, during selected periods of the growing season of winter wheat (Triticum aestivum L.) and after harvest in the year 2015, the growing season of winter barley (Hordeum vulgare L.) in spring 2016 and a catch crop mixture (Vicia sativa L., Pisum sativum L., Avena strigosa Schreb., Raphanus sativus L., Trifolium alexandrinum L., Phacelia tanacetifolia Benth., Guizotia abyssinica (L.f.) Cass.) in autumn 2016. 
The annual mean air temperature is $9.9^{\circ} \mathrm{C}$ and the annual precipitation sum is $698 \mathrm{~mm}$ (Graf et al. 2012). The maximum crop height ranged from 0.7 to $0.8 \mathrm{~m}$ in winter wheat and 0.95 to $1.05 \mathrm{~m}$ in winter barley. The soil is an Orthic Luvisol and the texture is silt loam according to the USDA classification (Graf et al. 2008). Table 1 gives an overview of the test days and the associated summary of the measurement properties and weather conditions.

Table 1 Profile measurements: measuring periods (number of 30-min mean profiles within the measurement period in brackets), measured variables $\left(\chi_{\mathrm{CO}_{2}}\right.$ and $\chi_{\mathrm{H}_{2} \mathrm{O}}$ are mole fractions of $\mathrm{CO}_{2}$ and $\mathrm{H}_{2} \mathrm{O}, u$ is wind speed and $T$ is temperature), weather condition (cloud amount in okta and wind speed in Beaufort number), canopy and profile height.

\begin{tabular}{|c|c|c|c|c|c|}
\hline Date & Time UTC & Variables & $\begin{array}{l}\text { Weather } \\
\text { condition }\end{array}$ & $\begin{array}{c}\text { Canopy } \\
\text { height } \\
(\mathrm{m})\end{array}$ & $\begin{array}{c}\text { Profile } \\
\text { height } \\
(\mathrm{m})\end{array}$ \\
\hline \multicolumn{6}{|l|}{ winter wheat } \\
\hline 14 April 2015 & $1515-1545$ & $\chi_{\mathrm{CO}_{2}}, \chi_{\mathrm{H}_{2} \mathrm{O}}$ & $1,2-3$ & 0.20 & 1.85 \\
\hline 20 Mai 2015 & 0850-0920 & $\chi_{\mathrm{CO}_{2}}, \chi_{\mathrm{H}_{2} \mathrm{O}}, u,(T)$ & 4,2 & 0.70 & 1.90 \\
\hline 1 June 2015 & $1630-1700$ & $\chi_{C O_{2}}, \chi_{H_{2} O}, u,(T)$ & 3,1 & 0.80 & 2.10 \\
\hline 7 June 2015 & 1530-1600 & $\chi_{\mathrm{CO}_{2}}, \chi_{\mathrm{H}_{2} \mathrm{O}}, u$ & 1,2 & 0.80 & 2.10 \\
\hline 8 June 2015 & 0630-1830 (10) & $\chi_{\mathrm{CO}_{2}}, \chi_{\mathrm{H}_{2} \mathrm{O}}, u$ & $1,2-3$ & 0.80 & 2.10 \\
\hline 30 June 2015 & $1100-1130$ & $\chi_{C_{2}}, \chi_{H_{2} O}, u,(T)$ & 0,1 & 0.80 & 2.10 \\
\hline 17 July 2015 & $1230-1300$ & $\chi_{C_{2}}, \chi_{H_{2} O}, u,(T)$ & 0,2 & 0.80 & 2.10 \\
\hline \multicolumn{6}{|l|}{ bare soil } \\
\hline 13 August 2015 & $1030-1100$ & $\chi_{C_{2} O_{2}}, \chi_{H_{2} O}, u,(T)$ & 0,2 & - & 2.10 \\
\hline 10 September 2015 & $1500-1530$ & $\chi_{C_{2}}, \chi_{\mathrm{H}_{2} \mathrm{O}}, u,(T)$ & 2,3 & - & 2.10 \\
\hline \multicolumn{6}{|l|}{ winter barley } \\
\hline 31 May 2016 & 1230-1300 & $\chi_{C_{2}}, \chi_{H_{2} O}, u,(T)$ & $6-7,2$ & 1.10 & 2.10 \\
\hline 6 June 2016 & 0730-1240 (5) & $\chi_{C O_{2}}, \chi_{H_{2} O}, u, T$ & $0,0-1$ & 0.95 & 2.10 \\
\hline 9 June 2016 & $0400-2300(20)$ & $\chi_{C_{2}}, \chi_{H_{2} O}, u, T$ & $0-1,0-2$ & 0.95 & 2.10 \\
\hline 10 June 2016 & $0000-1100(12)$ & $\chi_{C O_{2}}, \chi_{H_{2} O}, u, T$ & $1-2,0-1$ & 0.95 & 2.10 \\
\hline \multicolumn{6}{|l|}{ bare soil } \\
\hline 18 July 2016 & $1400-2200(9)$ & $\chi_{C_{2}}, \chi_{H_{2} O^{+}}, u, T$ & $0-2,0-1$ & - & 2.10 \\
\hline \multicolumn{6}{|l|}{ intercrop } \\
\hline 23 September 2016 & $0930-1200(4)$ & $\chi_{C_{2}}, \chi_{H_{2} O^{+}}, u, T$ & $1-5,2-3$ & 0.22 & 2.10 \\
\hline 23 November 2016 & $1100-1330(5)$ & $\chi_{\mathrm{CO}_{2}}, \chi_{\mathrm{H}_{2} \mathrm{O}^{+}}, u, T$ & 7,2 & 0.45 & 2.10 \\
\hline 24 November 2016 & $1400-2300(12)$ & $\chi_{\mathrm{CO}_{2}}, \chi_{\mathrm{H}_{2} \mathrm{O}}^{+}, u, T$ & $1,3-4$ & 0.45 & 2.10 \\
\hline 25 November 2016 & $0000-1530(25)$ & $\chi_{C O_{2}}, \chi_{H_{2} O^{+}}, u, T$ & $1,1-2$ & 0.45 & 2.10 \\
\hline 16 December 2016 & $1000-1330(8)$ & $\chi_{C_{2}}, \chi_{\mathrm{H}_{2} O}{ }^{+}, u, T$ & $1,2-3$ & 0.35 & 2.00 \\
\hline
\end{tabular}

Reference values of sensible heat flux $(H)$ and latent heat flux $(\lambda E)$, friction velocity $\left(u_{*}\right)$ and $\mathrm{CO}_{2}$ flux $\left(F_{C}\right)$ were calculated from measurements using a permanently-running eddy-covariance station at the Selhausen site. It operates with a three-dimensional sonic anemometer (Model CSAT-3, Campbell Scientific Inc., Logan, Utah, USA) to measure the wind vector and the sonic temperature. An open path infrared gas analyzer (Model LI- 7500, Li-Cor Inc. Biosciences, Lincoln, Nebraska, USA) measured the $\mathrm{CO}_{2}$ concentration and the absolute humidity $2.5 \mathrm{~m}$ above the surface, with a fetch of at least $120 \mathrm{~m}$ and up to $210 \mathrm{~m}$ in the prevailing west-south-west wind direction. The measurement frequency was 20 
$\mathrm{s}^{-1}$. Turbulent fluxes were calculated as 30-min averages using the 'TK3.11' software package, which includes rigorous quality control and correction procedures (Mauder and Foken 2011, Mauder et al. 2013). Here, only data of the highest quality (flag 0) were used. Gaps in the eddy-covariance dataset were filled with the REddyProc package after Reichstein et al. (2005).

Energy balance quantities were measured with a net radiometer (NR01, Hukseflux, Delft, the Netherlands), up to four self-calibrating soil heat-flux plates (HFP01SC, same manufacturer), and soil water content and temperature measurements in the layer above the heat flux plate for surface soil heat flux calculation following the calorimetric method (Appendix 1). Photosynthetically active radiation (PAR) was measured with a quantum sensor (Li190, LI-COR, Lincoln, Nebraska, USA). Both radiation instruments were mounted at a height of $2.5 \mathrm{~m}$.

An automated soil $\mathrm{CO}_{2}$ efflux chamber system (Li-8100, Li-Cor Inc. Biosciences, Lincoln, Nebraska, USA) was operated with at least three and up to four long-term chambers. The chambers were placed on PVC soil collars of $0.2 \mathrm{~m}$ in diameter and a height of $0.07 \mathrm{~m}$, which were inserted $0.05 \mathrm{~m}$ into the soil. The closing interval for each chamber was $30 \mathrm{~min}$, and it was closed for $90 \mathrm{~s}$ for each flux measurement. $\mathrm{CO}_{2}$ and water vapour concentrations as well as chamber headspace temperature were measured every second. The $\mathrm{CO}_{2}$ concentration was corrected for changes in air density and water vapour dilution. The soil respiration $\left(R_{\mathrm{S}}\right)$ was calculated by fitting a linear regression to the corrected $\mathrm{CO}_{2}$ concentrations from $30 \mathrm{~s}$ after closing until reopening.

Information about the leaf and plant area index $(P A I)$ and green area index $(G A I)$ over the whole plant growing seasons were collected in intervals of four weeks in field with a LAI-2200 plant canopy analyzer (Li-Cor Inc. Biosciences, Lincoln, Nebraska, USA) and with a destructive method (LI-3100C area meter, Li-Cor Inc. Biosciences, Lincoln, Nebraska, USA). On dates where optical and destructive measurements of $P A I$ were taken, both methods compared well, such that uncorrected optical $P A I$ values are reported for days where no destructive measurements were available. In June and November 2016, vertical profiles of $P A I$ were measured manually in winter barley and catch crop from the soil surface up to the canopy top every $0.05 \mathrm{~m}$ with a SunScan-System SS1 (Delta-T devices, Cambridge, UK).

On profile measurement days (see Table 1), the elevator system was placed at a distance of $15-30 \mathrm{~m}$ from the eddy-covariance station at a day-dependent direction to prevent both installations from obstructing the fetch of each other.

\subsection{Profile measurement set-up}

The system measures mole fractions (amount of substance per mole of moist air) of $\mathrm{CO}_{2}\left(\chi_{\mathrm{CO}_{2}}\right)$ and water vapour $\left(\chi_{\mathrm{H}_{2} \mathrm{O}}\right)$ with a resolution of $20 \mathrm{~s}^{-1}$ between the soil surface, the plant canopy and the atmosphere while continuously moving the intake of a sampling tube between the ground surface and a maximum height, which was around $2 \mathrm{~m}$ in our case. The measurement system was continuously improved, such that the schematic illustration in Fig. 2 represents the device version in the last measuring period starting in July 2016 (see Table 1 and Appendix 1). The elevator consists of a camera tracking slide (c) for moving time-lapse photography (Dynamic Perception LLC, Ann Abor, Minnesota, USA) mounted vertically to a 
tripod (b). A motor is mounted on the carriage (slider) (f) which drives up and down on a toothed drive belt $(\mathrm{d})$. Two cuffs (e) are attached to the frame at the upper and lower end position, which trigger reversion of the sense of motion on contact. The time of these events is logged to a text file on a computer. A rotation sensor on the slider, using the same toothed belt, provides position data with a nominal resolution of approximately $0.003 \mathrm{~m}$, which are logged as counted steps to the same text file at intervals of $0.17 \mathrm{~s}$.

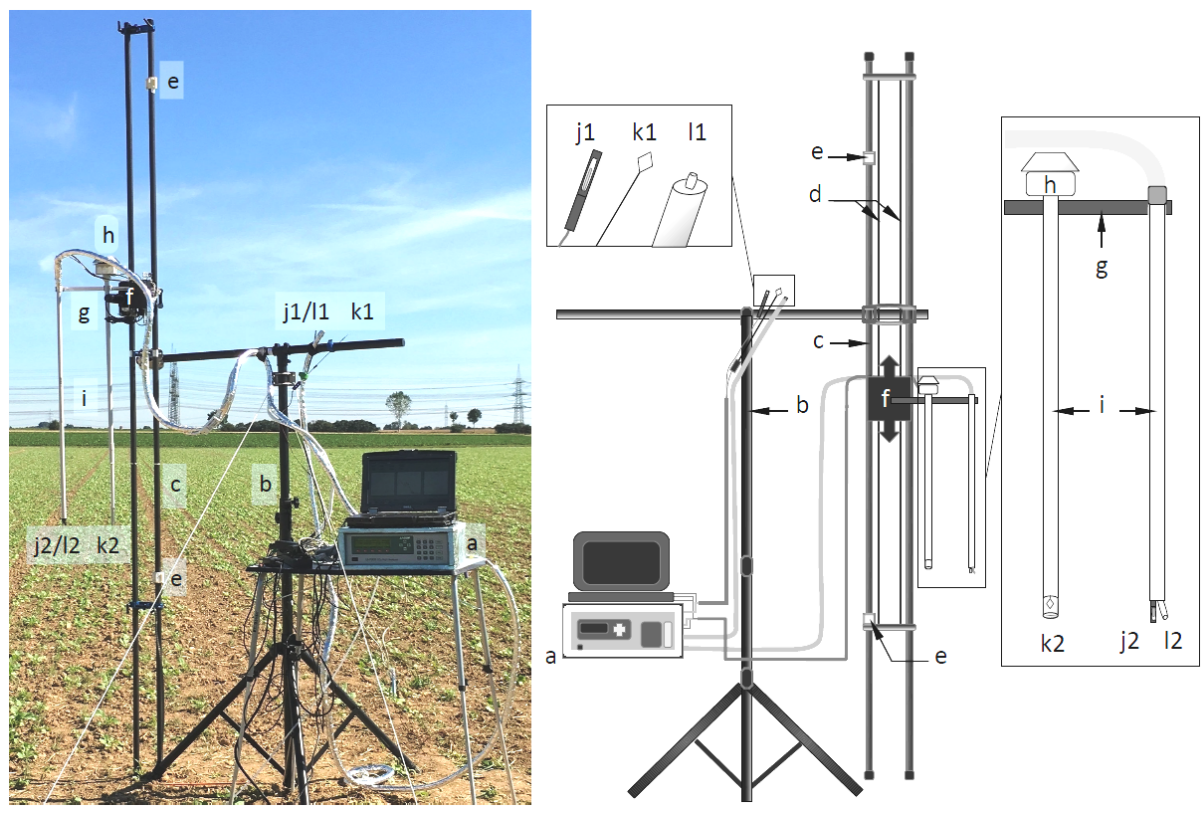

Fig. 2 The profile-measurement set-up in the field (left) and as a schematic diagram (right). (a) gas analyzer, (b) tripod, (c) tracking slide, (d) toothed drive belt, (e) upper and lower limiting ring (cuff), (f) carriage, (g) extension arm, (h) thermocouple ventilation unit, (i) conduit, (j) fixed-height (1) and moving (2) hot-wire anemometer, (k) fixed-height (1) and moving (2) thermocouple and (1) fixed-height (1) and moving (2) inlet tubes from the gas analyzer.

$\chi_{\mathrm{CO}_{2}}$ and $\chi_{\mathrm{H}_{2} \mathrm{O}}$ were measured using a closed-path, differential infrared absorption gas analyzer (LI7000, Li-Cor Inc. Biosciences, Lincoln, Nebraska, USA) (a). Each of the two cells of the analyzer was connected through a 1-um filter to a polyethylene tube of $0.0035 \mathrm{~m}$ inner diameter. The outlets of the cells were connected to the internal pump of the LI7000, which was run at maximum speed, leading to a flow rate of about $30 \mathrm{l} \mathrm{h}^{-1}$ through each tube. $\chi_{\mathrm{CO}_{2}}$ and $\chi_{\mathrm{H}_{2} \mathrm{O}}$ in both cells and diagnostic variables of the LI7000 were logged at intervals of $0.05 \mathrm{~s}(20$ $\mathrm{s}^{-1}$ ). While the end of one tube (11) was attached to the tripod at a fixed height of approximately $2 \mathrm{~m}$, the other one was attached to an extension $(\mathrm{g})$ on the carriage (Fig. 2f). Tube length, heating and insulation changed over time as indicated in Table 1 and described in Appendix 1.

Wind speed was measured using two hot-wire anemometers (8455- 075-1, TSI, Shoreview, Minnesota, USA) (j), one of which was fixed at approximately $2 \mathrm{~m}$ (j1), 
while the other $(\mathrm{j} 2)$ was attached near the tip of the conduit, such that the sensor was level with the tube intake (12) and about $0.02 \mathrm{~m}$ away from it. Temperature was measured by two fine-wire thermocouples (FW3, Campbell Scientific, Logan,

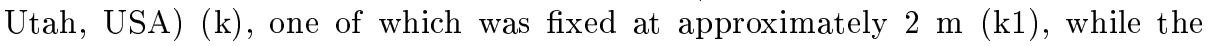
other one $(\mathrm{k} 2)$ was attached to a second conduit, the junction tip level with the other moving measurements and $0.2 \mathrm{~m}$ away from them. While the fixed-height thermocouple was operated unshielded, the moving thermocouple was shielded against direct contact with plants or soil by an empty conduit with a diameter of $0.015 \mathrm{~m}$, with a fine fiberglass mesh at the tip and a ventilation unit (h) at the other end of the conduit, which produced a flow rate at the tip of $3.7 \mathrm{~m} \mathrm{~s}^{-1}$. This final wind and temperature set-up was the result of stepwise improvements described in Appendix 1.

\subsection{Profile data processing}

While the continuously moving set-up allows us to chose the temporal and vertical resolution of mean profiles during data processing, we consistently use timeaveraging blocks of $30 \mathrm{~min}$. For each such block, the logged slider position data in steps was assembled to the height by scaling the minimum step number to 0 $\mathrm{m}$ and the maximum step number to the topmost measuring height during the respective measuring period (approximately $2 \mathrm{~m}$, for details see Table 1 ). Values missing after adding the position dataset (0.17-s resolution) to the gas concentration, temperature and wind-speed data (0.05-s resolution) via the nearest time stamp, were filled using linear interpolation.

Physically unrealistic values were filtered out before the calculation of mean profiles by a plausibility screening and a spike detection algorithm based on median absolute deviation $(M A D)$ limits, similar to the one described in Mauder et al. (2013). However, the chosen limits were extended to accommodate the larger variability of the moving sensor data (Table 2).

Table 2 Thresholds used for plausibility tests, spike detection tolerances and shift limits (in s) for lag removal. Spike tolerances are given in equivalent standard deviations, i.e., in the median absolute deviation $(M A D)$ divided by 0.6745 , which matches one standard deviation in normal distributions but is less outlier-sensitive otherwise (see Mauder et al. 2013).

\begin{tabular}{|c|c|c|c|}
\hline Variable & Consistency limits & Spike tolerance & Shift limits (s) \\
\hline$\chi_{C O_{2 f i x}}$ & 200 to $900 \mu \mathrm{mol} \mathrm{mol}{ }^{-1}$ & $9 \sigma_{e q}$ & -30 to 0 \\
\hline$\chi_{C O_{2 v a r}}$ & 200 to $900 \mu \mathrm{mol} \mathrm{mol}-1$ & $20 \sigma_{e q}$ & -30 to 0 \\
\hline$\chi_{H_{2} O_{f i x}}$ & 0 to $50 \mathrm{mmol} \mathrm{mol} \mathrm{m}^{-1}$ & $9 \sigma_{e q}$ & -30 to 0 \\
\hline$\chi_{\mathrm{H}_{2} \mathrm{O}_{v a r}}$ & 0 to $50 \mathrm{mmol} \mathrm{mol}^{-1}$ & $20 \sigma_{e q}$ & -30 to 0 \\
\hline$u_{f i x}$ & 0 to $10 \mathrm{~m} \mathrm{~s}^{-1}$ & $9 \sigma_{e q}$ & -10 to 10 \\
\hline$u_{\text {var }}$ & 0 to $10 \mathrm{~m} \mathrm{~s}^{-1}$ & $20 \sigma_{e q}$ & -10 to 10 \\
\hline$T_{f i x}$ & 0 to $40{ }^{\circ} \mathrm{C}$ & $9 \sigma_{e q}$ & -20 to 10 \\
\hline$T_{\text {var }}$ & 0 to $40{ }^{\circ} \mathrm{C}$ & $20 \sigma_{e q}$ & -20 to 10 \\
\hline$p$ & 70 to $110 \mathrm{kPa}$ & $9 \sigma_{e q}$ & - \\
\hline elevator speed & -0.2 to $0.2 \mathrm{~m} \mathrm{~s}^{-1}$ & - & - \\
\hline
\end{tabular}

The response times of the wind and temperature sensors, electronic delays, and 
to the position data. Different delays for $\mathrm{CO}_{2}$ and $\mathrm{H}_{2} \mathrm{O}$, in spite of the common tube and analyzer system, are well-known from closed-path eddy-covariance measurements due to the higher adhesivity of water vapour to tube walls (Ibrom et al. 2007). These delays are determined empirically by a hysteresis minimization algorithm. Within possible shift limits (see Table 2), the variables are shifted with respect to the position data in 0.05 -s steps, and for each candidate delay and variable a preliminary vertical profile is computed, including the profile of the standard deviation of the variable

$$
\sigma_{x, h}(\Delta t)=\sqrt{\frac{1}{M(h)} \sum_{i=1}^{M(h)}[x(h, i, \Delta t)-\bar{x}(h, \Delta t)]^{2}},
$$

where $x$ is the variable of interest, $\Delta t$ the shift backwards in time according to the respective candidate delay, and $M$ the number of individual 0.05-s measurements $i$ available in the respective height bin after shifting $x$ by $\Delta t$ with respect to the position data. Here, the height bins are $0.025 \mathrm{~m}$ high. The final delay for each variable is the one that minimizes the average of this standard deviation over all heights,

$$
\bar{\sigma}_{x}(\Delta t)=\sqrt{\frac{1}{N} \sum_{h=1}^{N} \sigma_{x, h}^{2}(\Delta t),}
$$

where $N$ is the number of height bins $h$, and the overbar denotes averaging. Required time shifts determined this way for the moving sensors were assumed to be equally applicable to the respective fixed-height sensor, due to the identical measurement systems and tube lengths. Delay correction of the fixed-height measurements is not of importance here, but might be relevant when analyzing e.g. fast fluctuations of moving sensor signals in comparison to those of fixed-height measurements.

After determining the optimal time lag $\Delta t_{\text {opt }}$, Eq. 1 can also be used to determine the uncertainty (stochastic error) of the final profile of $x$ at each height separately. To provide the uncertainty as a $95 \%$ confidence interval, we use the equation,

$$
C_{0.95, x, h}=1.96 \frac{\sigma_{x, h}\left(\Delta t_{o p t}\right)}{\sqrt{M_{\text {ind }}}},
$$

where $M_{i n d}$ is the number of statistically independent samples per height bin, which may be smaller than $M$ due to oversampling of an autocorrelated time series, a problem for which different strategies exist in the framework of eddycovariance data processing (Lenschow et al., 1994; Finkelstein and Sims, 2001; Moene and Michels, 2002; Van Dijk et al., 2004; Graf et al., 2010; Billesbach, 2011; Mauder et al., 2013). In our dataset, the samples contributing to $\bar{x}_{h}$ have a clustered temporal structure, with $M=M_{1} \cdot M_{2}, M_{1}$ being the number of passes through a height bin during the averaging interval (approximately 50 in $30 \mathrm{~min}$ ) and $M_{2}$ the average number of samples recorded during a single pass ( 8 in the time of approximately $0.4 \mathrm{~s}$ needed to pass each height bin). The integral time scale of atmospheric turbulence for our variables of interest in the atmospheric boundary layer is typically between 0.4 and $6 \mathrm{~s}$ (Lenschow et al., 1994; Finkelstein and Sims, 2001). A worst-case assumption that the $M_{2}$ consecutive samples during a single pass of a height bin do not notably contribute to a reduction in uncertainty leads 
to a conservative estimate $M_{i n d} \approx M_{1}$. This assumption will be revisited in the results, Sect. 3.1, in an analysis with synthetically-reduced raw data acquisition frequency.

Profile measurements are frequently used to estimate the contribution of storage changes below the eddy-covariance measurement level to possible differences between the measured turbulent flux and surface exchange, particularly in case of $\mathrm{CO}_{2}$. To receive a storage term estimate that is in phase with the flux time series and does not suffer from additional methodological low-pass filtering, we averaged three consecutive ascents and descents at the beginning and at the end of each 30-min time block to yield near-instantaneous $\chi_{\mathrm{CO}_{2}}$ profiles representing approximately the first and last $3.5 \mathrm{~min}$. After conversion to units of $\mu \mathrm{mol} \mathrm{m}{ }^{-3}$ using the according temperature profile and average pressure, the height-integrated concentration differences and exact time spans between consecutive near-instantaneous profiles were used to estimate the average storage change in $\mu \mathrm{mol} \mathrm{m} \mathrm{m}^{-2} \mathrm{~s}^{-1}$ for each 30-min profile measurement, but also for each 30-min break in the case of hourly repeated profile measurements on 9-10 June 2016 and 18 July 2016 (see Table 1 and Sect. 3.3).

\subsection{Profile shape validation and flux determination using Monin-Obukhov} similarity theory

During the post-harvest measurements above bare soil and short catch crop canopy (canopy height $\leq 0.22 \mathrm{~m}$ ), a large portion of the total profile should follow surfacelayer scaling. Therefore, we analyzed those measurements in the framework of Monin-Obukhov similarity theory to check the validity of the measurement and raw-data processing approach, derive $\mathrm{CO}_{2}$, sensible and latent heat fluxes, and compare them to eddy-covariance and chamber measurements.

Flux derivation from surface-layer profiles is based on the integrated flux-profile relations for momentum, heat and mass as described in Appendix 2. Based on these equations (Eqs. 9 to 14 ) the friction velocity $u_{*}$ and the flux of sensible heat or other scalars can be calculated from the slope of a linear regression between logarithmized height $\ln (z)$ and wind speed $u$, respectively $\ln (z)$ and potential temperature $\theta$ or another scalar $X$ (Arya, 2001; Foken, 2006),

$$
\begin{gathered}
\ln z-\psi_{m}\left(\frac{z-d}{L}\right)=\frac{\kappa}{u_{*}} u+\ln z_{0}, \\
\ln z-\psi_{h}\left(\frac{z-d}{L}\right)=\frac{\alpha_{0} \kappa}{\theta_{*}} \theta-\frac{\alpha_{0} \kappa}{\theta_{*}} \theta_{0}+\ln z_{0 \theta},
\end{gathered}
$$

where $\psi_{m}$ and $\psi_{h}$ are the stability corrections for momentum exchange and exchange of sensible heat, $z_{0}$ and $d$ are the aerodynamic roughness length and displacement height, $z_{0 \theta}$ is the scalar roughness length, $L$ is the Obukhov length, $\kappa$ is the von Karman constant, the coefficient $\alpha_{0}=1.25, \theta$ is the potential temperature, $\theta_{0}$ is the potential temperature at $z-d=z_{0 \theta}$, and $\theta_{*}$ is the scaling parameter for temperature according to Eq. 13 (Appendix 2). Apart from the measured profiles, $z_{0}$ and $d$ are needed as well as an initial estimate of $L$, which can then be improved by iteration. To estimate stability values from the measured vertical profiles only, $u_{*}$ and the sensible heat $H$ were replaced in Eq. 12 (Appendix 2) by the surface-layer gradient equations (Foken, 2006): 


$$
\begin{gathered}
u_{*}=\sqrt{-\overline{u^{\prime} w^{\prime}}}=\frac{\kappa}{\varphi_{m}\left(\frac{z-d}{L}\right)} \frac{\partial u}{\partial \ln (z-d)}, \\
\overline{w^{\prime} \theta^{\prime}}=-\frac{\alpha_{0} \kappa u_{*}}{\varphi_{h}\left(\frac{z-d}{L}\right)} \frac{\partial \theta}{\partial \ln (z-d)},
\end{gathered}
$$

where $\varphi_{m}$ and $\varphi_{h}$ are the universal functions for momentum and heat. Thus we achieve the Obukhov length in the form

$$
L=\frac{\theta}{g \alpha_{0}} \frac{1}{\partial \theta} \frac{\partial u^{2}}{\partial \ln (z-d)} \frac{\varphi_{m^{2}}}{\varphi_{h}},
$$

where $g$ is the acceleration due to gravity, and the gradients in the term $\frac{1}{\partial \theta} \frac{\partial u^{2}}{\partial \ln (z-d)}$ were estimated from the vertical profiles of wind and potential temperature by two linear regressions of $\theta$ and $\ln (z)$, respectively, against $u$. For the regression of each variable we used an algorithm, which iteratively omitted data points at one or both ends of the profile until the p-value of the regression was optimized, for example, to prevent the influence of profile values measured below the surface layer. The universal function for momentum $\varphi_{m}$ and heat $\varphi_{h}$ is in the unstable case $\varphi_{m}^{2} \approx \varphi_{h}$ (Foken, 2006) and thus neglected in the first estimate of $L$. The roughness length $z_{0}$ was computed from the offset of the regression of $\ln (z)$ against $u$. To account for a possible displacement height $d$, the whole procedure was repeated for all $d$ values between zero and the canopy height, until the $R^{2}$ value of $\ln (z)$ against $u$ is maximized.

Now, with $d$ and $z$ known and a first estimate of $L$ and $z_{0}$ available, we can compute first momentum and heat flux estimates with Eq. 4 and 5. After that, a second and third estimate of the stability was performed by calculating a new $L$ with the resulting heat and momentum flux and the original definition (Eq. 12). After that, fluxes for the other scalars $\left(\mathrm{H}_{2} \mathrm{O}\right.$ and $\left.\mathrm{CO}_{2}\right)$ were estimated in analogy to Eq. 5. For diagnostic purposes, the model profiles consistent with the estimated fluxes and aerodynamic parameters can be derived by applying the basic equations (9) to (11) in forward mode again, and compared to the measured profiles.

\section{Results and discussion}

\subsection{Raw data processing diagnostics}

An example is given in Fig. 3 to demonstrate the effect of profile data processing described in Sect. 2.4. Figure 3a shows a raw data time series of $\chi_{\mathrm{CO}_{2}}$ from the moving and the fixed height sensor for an interval of 30 min measured in winter barley. The high and low peaks of $\chi_{\mathrm{CO}_{2}}$ reflect the source at the soil surface and the mid canopy sink, respectively. Both time series coincide when the moving sensor was at the approximate height of the fixed one. Figure 3b and Fig. 3c show the same data for every ascent and descent as a function of moving sensor position before and after lag removal. Averaged mean profiles before and after lag removal are displayed in Fig. 3c. Before lag determination, the standard deviation and resulting uncertainty (see Eq. 1 and 3) is larger than with the applied final delay. The final delay was calculated by Eq. 1 and is highlighted in the development of 

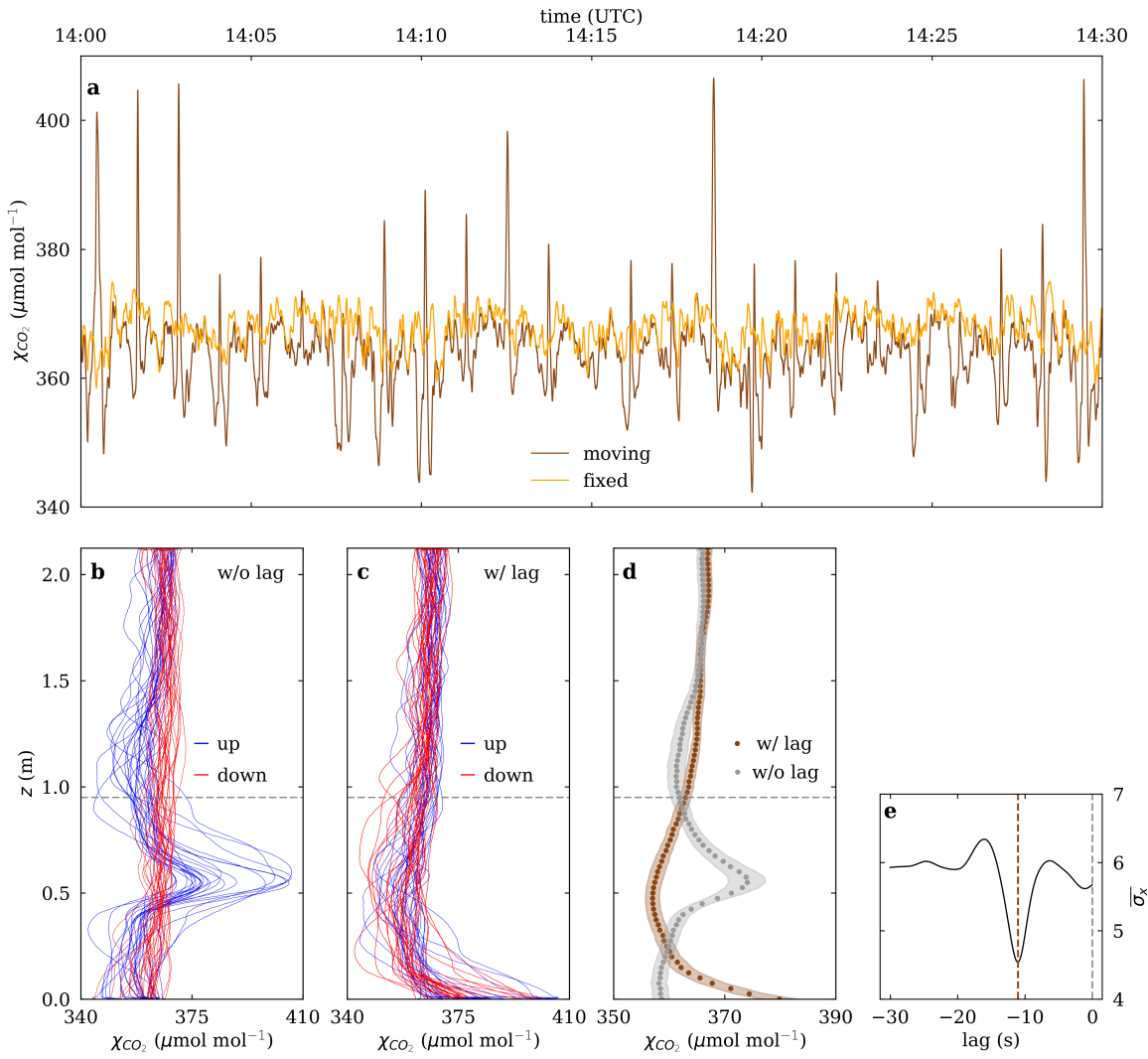

Fig. 3 a) Raw data time series of $\chi_{\mathrm{CO}_{2}}$ for the moving and the fixed height sensor from 9 June 2016 from 1400 to 1430 UTC. b) Vertical profile of $\chi_{\mathrm{CO}_{2}}$ vs. height $z$ (m, a.g.l) at 9 June 2016 from 1400 to 1430 UTC with all upward and downward soundings before lag removal procedure (w/o lag) and c) after lag removal procedure (w/ lag). d) 30-min mean profile of $\chi_{\mathrm{CO}_{2}}$ averaged over all profiles before and after lag removal, shaded areas indicate the $95 \%$ confidence interval resulting from the standard deviation between individual samples and e) development of $\bar{\sigma}_{x}$ as a function of the lag. Dashed lines in b, c and d declare the canopy height.

$\bar{\sigma}_{x}$ (Eq. 2) as a function of the delay in Fig. 3, in this case raw data were lagged by $11 \mathrm{~s}$.

Figure 4 demonstrates that the estimated lag time for $\chi_{\mathrm{H}_{2} \mathrm{O}}$ is longer than for $\chi_{\mathrm{CO}_{2}}$ (a), and increases with relative humidity (b). During the first 24 -h measurement in June 2016 (Sect. 3.3), we found that in conditions with high air humidity (mostly nocturnal situations) the determination of the lag for $\chi_{\mathrm{H}_{2} \mathrm{O}}$ failed. Lags in the signal of closed-path analyzers can be subject to adsorption of water vapour to the inner tube walls. The extent of condensation is related to the relative air humidity, but also to the wall material (Bloom et al., 1980), its age, and to the presence of aerosols (Mammarella et al., 2009; Nordbo et al., 2013). Humidity also has an effect on the lag of the measured $\chi_{\mathrm{CO}_{2}}$, although in an attenuated form, due to solubility in water. We minimized this problem in the following observation periods by heating and insulating the sampling tube (Appendix 1). A linear 

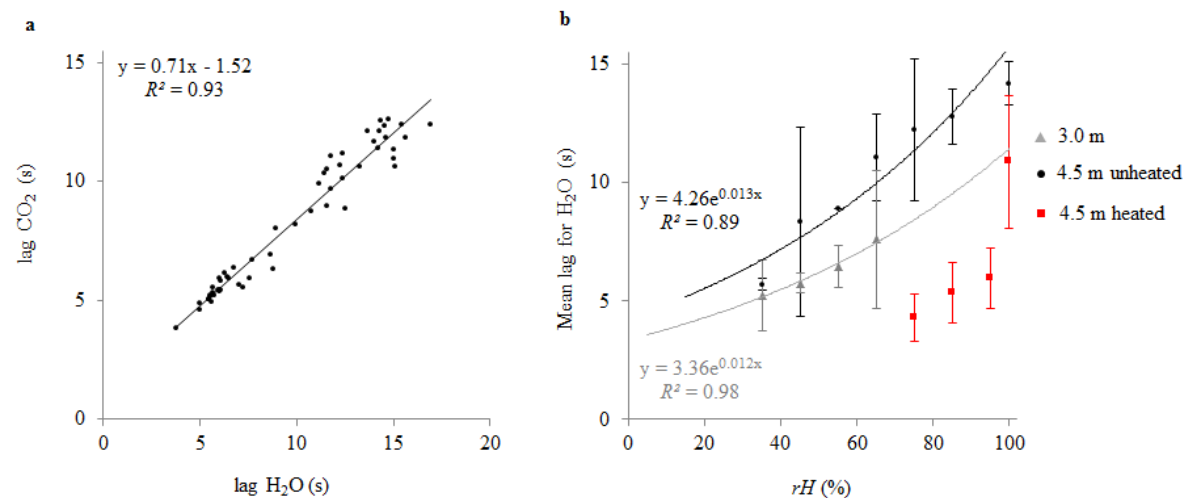

Fig. 4 a) Linear dependence between the determined lag time (s) of $\chi_{\mathrm{H}_{2} \mathrm{O}}$ and $\chi_{\mathrm{CO}_{2}}$. b) Lag (s) of $\chi_{\mathrm{H}_{2} \mathrm{O}}$ averaged over humidity classes with error bars indicating one standard deviation from the mean, plotted against relative humidity $(r H)$. Lag times for tube length of $3 \mathrm{~m}$ (triangles) and $4.5 \mathrm{~m}$ unheated (dots) and $4.5 \mathrm{~m}$ heated (square).

humidity-lag relation might be fitted to each of the sub-datasets (3-m tube length, $4.5 \mathrm{~m}, 4.5 \mathrm{~m}$ heated) shown in Fig. 4. However, consideration of all sub-datasets across the larger humidity range and literature (Mammarella et al., 2009) suggest a progressive relationship. The axis intercepts of empirical exponential fits to the unheated datasets with different tube lengths have a ratio of 1.3 , which roughly reflects the length change (factor 1.5) and thus suggests a proportionality between tube length and lag time. The dataset with activated tube heating does not allow for a robust intercept estimation due to missing low humidity situations, but clearly shows an accelerating effect on lag time. A sharp increase above 90 $\%$ suggests that the heating power may be insufficient to optimally handle fully saturated conditions.

Figure 5 shows the effect of a simulated lower data acquisition frequency on the resulting time-averaged profiles. A decrease from $20 \mathrm{~s}^{-1}$ to $10 \mathrm{~s}^{-1}$ yields hardly visible effects (not shown). For the variables $\chi_{\mathrm{CO}_{2}}$ and $\chi_{\mathrm{H}_{2} \mathrm{O}}$ almost the same is true for $5 \mathrm{~s}^{-1}$, indicating that the physical low-pass filtering properties of the closedpath system are on the same order of magnitude. At $1 \mathrm{~s}^{-1}$, scatter considerably increases for all variables, and the temperature profile is subject to a failure of lag determination. In this case, the target vertical resolution $(0.025 \mathrm{~m})$ and given elevator speed $\left(0.06 \mathrm{~m} \mathrm{~s}^{-1}\right)$ do not ensure any more that the raw values contributing to a single profile height stem from all of the approximately 50 soundings per 30 min. To avoid this, the measurement frequency should be at least $5 \mathrm{~s}^{-1}$ with the given speed and target resolution. The increase in scatter visible in Fig. 5 largely confirms the assumption made in Sect. 2.4 that measurement uncertainty of the final profiles is mostly determined by the number of elevator passes through a height bin during which at least one raw record was sampled, and less by the number of such raw records during an individual pass. 

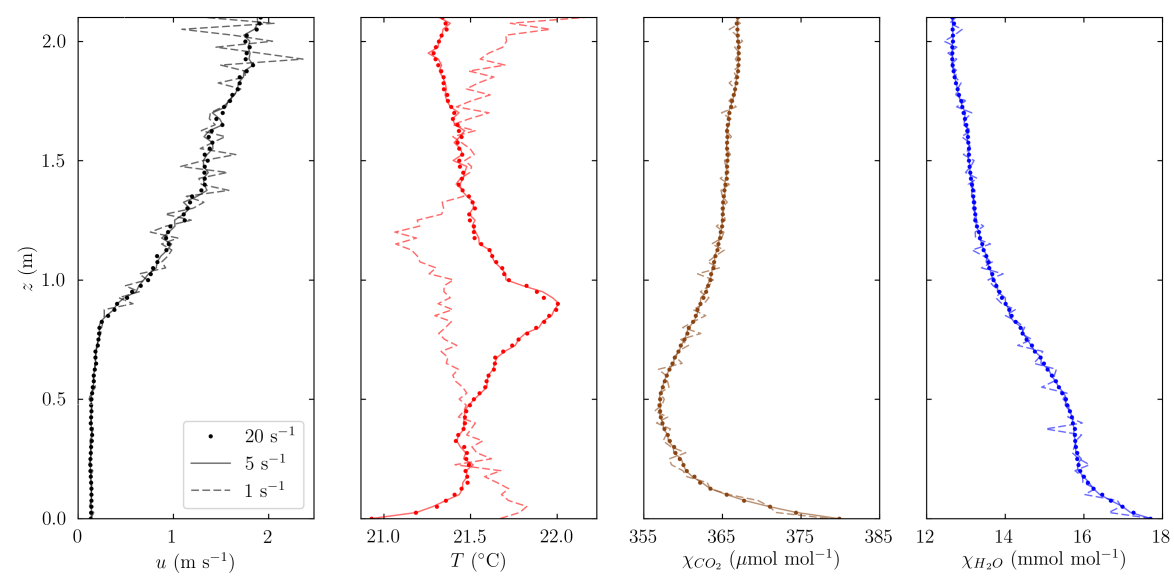

Fig. 5 30-min mean profiles of wind speed $u$, temperature $T, \chi_{\mathrm{CO}_{2}}$ and $\chi_{\mathrm{H}_{2} \mathrm{O}}$ at 2016-0609 1400-1430 UTC based on the original raw data acquisition frequency of $20 \mathrm{~s}^{-1}$ (dots) and simulated lower resolutions of $5 \mathrm{~s}^{-1}$ (lines) and $1 \mathrm{~s}^{-1}$ (dashed lines).

\subsection{Profiles of $\mathrm{CO}_{2}$ and $\mathrm{H}_{2} \mathrm{O}$ over a winter wheat plant growing season}

In 2015, profile measurements were carried out during chosen growth stages of winter wheat as well as after harvest and cultivation. The profiles shown in Fig. 6 were collected during different hours of the day (0850-1630 UTC, see Table 1), but care was taken to have at least one pair of measurements under comparable weather conditions during the different growth stages and we generally avoided rainy and overcast conditions (maximal amount of cloud about 4 oktas), while covering a large range of wind-speed conditions (30-min averages between $0.3-5$ $\left.\mathrm{m} \mathrm{s}^{-1}\right)$.

Figure 6 shows the mean profiles of $\chi_{\mathrm{CO}_{2}}$ in $\mu \mathrm{mol} \mathrm{mol}{ }^{-1}$ and $\chi_{\mathrm{H}_{2} \mathrm{O}}$ in $\mathrm{mmol} \mathrm{mol}{ }^{-1}$ (amount of substance per mole of moist air) versus height $(z)$ above ground level (a.g.l.) in the growing season of winter wheat 2015. In the middle of April (Fig. $6 a)$, when the plants were in an early vegetative stage, there was only a small reduction in $\chi_{\mathrm{CO}_{2}}$ in the plant stand with a low $\chi_{\mathrm{CO}_{2}}$ accumulation near the soil surface. From the middle of May until end of June (Fig. 6b-e), the crops reached their highest growth rate and $G A I$, with high gradients of $\chi_{\mathrm{CO}_{2}}$ between the soil

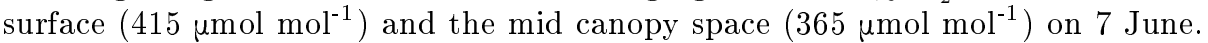
At the same time, $F_{C}$ reached its highest negative daily means, which underpins the $\mathrm{CO}_{2}$ uptake by the plants.

$\chi_{\mathrm{H}_{2} \mathrm{O}}$ usually decreased with height in agreement with the fact that during the day there are only sources and no sinks, both at the ground surface (evaporation) and in the canopy (transpiration). However, on 1, 7 and 30 June a zone of stagnation can be seen between both sources. Later in summer (Fig. 6f), when grains were formed and leaves turned yellow, the $G A I$ began to decrease, until photosynthesis finally ceased. On 17 July, two weeks before harvest, the profiles of $\chi_{\mathrm{CO}_{2}}$ and $\chi_{\mathrm{H}_{2} \mathrm{O}}$ showed only a source at the surface due to soil respiration and evaporation, indicating no significant transpiration and respiration in the plant canopy. After harvesting, both profiles measured over bare soil (Fig. 6g and h) de- 

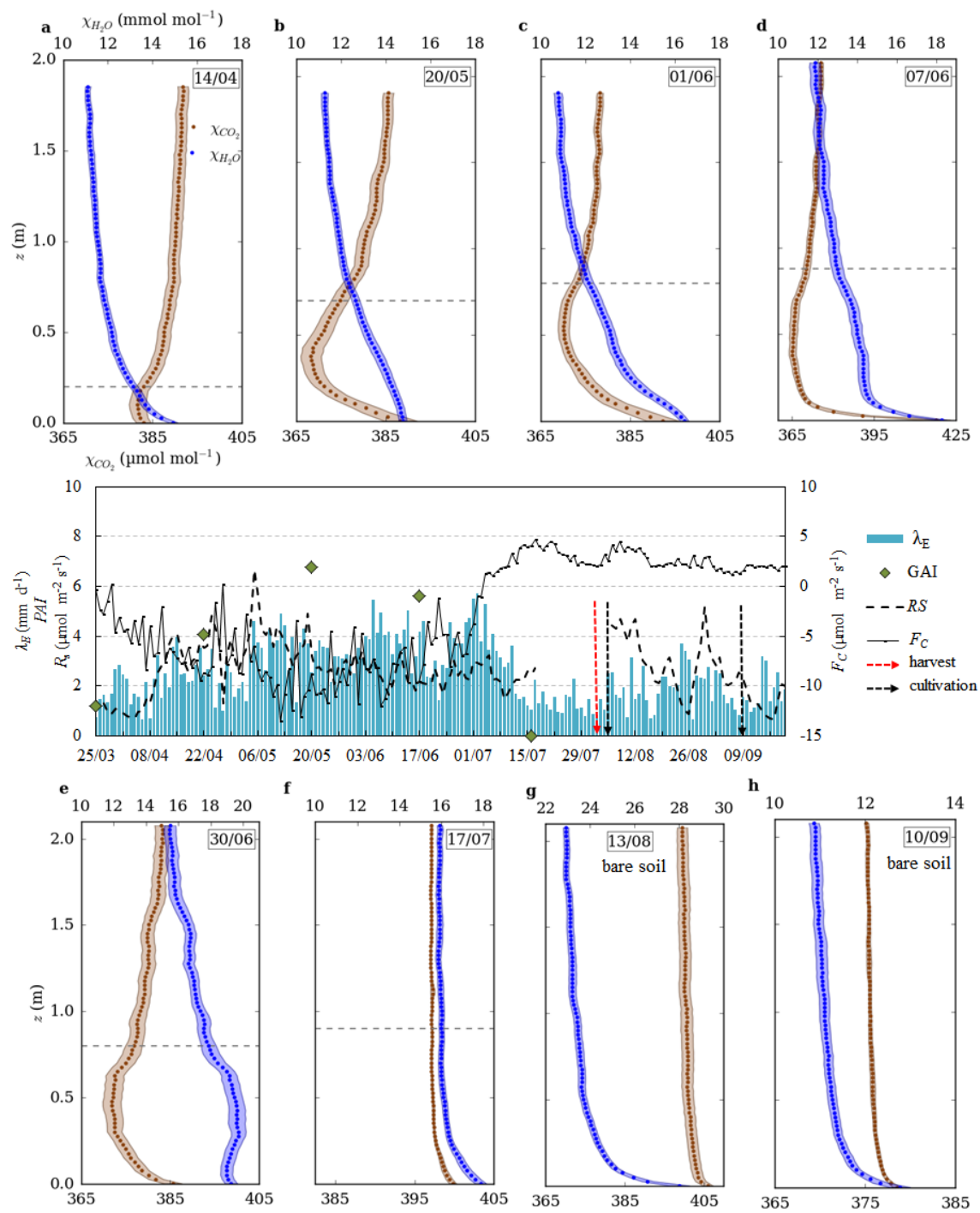

Fig. 630 -min mean profiles of $\chi_{\mathrm{CO}_{2}}$ and $\chi_{\mathrm{H}_{2} \mathrm{O}}$ vs. height $z$ (m, a.g.l.) during selected periods of the growing season and after harvest (bare soil) of winter wheat. Dashed lines declare the plant height. Daily means and sums of $\mathrm{CO}_{2}$ flux $F_{C}$ and evapotranspiration $E$, the PAI and daily means of soil respiration $R_{s}$. No soil respiration data were available from 17 July until 6 August 2015 because of instrumental removal due to harvest and cultivation.

picted a similar logarithmic pattern, but differ in the absolute value. We suppose that the large differences in $\chi_{\mathrm{CO}_{2}}$ and $\chi_{\mathrm{H}_{2} \mathrm{O}}$ covered by the profiles between these two dates are a product of different source strengths on the one hand and different turbulent exchange on the other. The measurement on 13 August took place between 1030 and 1100 UTC, thus earlier than most other measurements within the growing season of winter wheat. Remaining $\mathrm{CO}_{2}$ enrichment from the nocturnal boundary layer in the surrounding atmosphere may have led to a higher $\chi_{\mathrm{CO} 2}$ 
level. Furthermore, the different weather conditions might have had an influence. The measurement on 13 August was characterized by $10{ }^{\circ} \mathrm{C}$ higher air and soil temperature (thus enhancing respiration, as seen in the soil respiration and $F_{C}$ measurements), and by a $1.5 \mathrm{~m} \mathrm{~s}^{-1}$ lower wind speed and at the particular time of day also a higher evapotranspiration $(E)$ compared to the measurement on 10 September. In general, concentration gradients, including those in plant canopies, are determined by the interplay between source strength, mixing intensity and the background concentration in the surrounding boundary layer.

3.3 Diurnal cycle of profiles of $\mathrm{CO}_{2}, \mathrm{H}_{2} \mathrm{O}$, temperature and wind speed over winter barley and bare soil

Longer measurements covering day and night conditions (cf. Table 1) were performed to find out how the profiles change over the day in different vegetation covers. As an example, we present here a 30-h measurement in winter barley on 9-10 June 2016 and an 8-h measurement after the harvesting of barley over cultivated bare soil (rough surface with soil aggregates and remaining stubble) on 18 July 2016 (Fig. 7). Measurements for one mean profile were performed during the first $30 \mathrm{~min}$ of every full hour. The mean height of barley was about $0.95-1.0 \mathrm{~m}$ and the entire height range of the profile was $2.1 \mathrm{~m}$.

The cumulative $P A I$ of the barley canopy was 6.3 , of which $83 \%$ were approximately homogeneously distributed between the canopy top and $0.3 \mathrm{~m}$ a.g.l., corresponding to $6.5 \mathrm{~m}^{2} \mathrm{~m}^{-3}$. In the lowermost $0.3 \mathrm{~m}$, density was lower with 3.7 $\mathrm{m}^{2} \mathrm{~m}^{-3}$

The measurements in barley occurred on one of the first dates with a shielded, ventilated thermocouple (see Sect. 2.3), but from 0700 to 1200 UTC the ventilation was interrupted due to a power cable failure (hatched area in Fig. 7a). $\chi_{H_{2} O}$ profiles were not evaluable on 9-10 June from 0400 to 0500 UTC and between 1900 and 0600 UTC (marked by hatched areas in Fig. 7d) due to water condensation in the inner tube walls during situations with high air humidity and radiative cooling of the tubes (see Sect. 3.1). Before the bare soil measurement period, tube insulation and heating was installed (see Appendix 1).

The $\chi_{\mathrm{CO}_{2}}$ values measured in barley (Fig. 7c) decreased from 0400 UTC to $1200 \mathrm{UTC}$ by more than $50 \mu \mathrm{mol} \mathrm{mol}{ }^{-1}$ in the mid canopy. The lowest values were about $12 \mu \mathrm{mol} \mathrm{mol}{ }^{-1}$ lower than those at $2.1 \mathrm{~m}$ a.g.l, occurring in the mid canopy during mid-day simultaneously to the highest $P A R$ values. This drawdown due to plant uptake is connected with high transpiration. Consequently, $\chi_{\mathrm{H}_{2} \mathrm{O}}$ in the canopy space was higher than in the air above the canopy. The highest values were found directly above the soil surface, due to evaporation, and in the mid canopy in the midday hours. High $\chi_{\mathrm{H}_{2} \mathrm{O}}$ near the soil surface below the barley canopy during the day is due to soil respiration, lower light intensity caused by shadowing, a low quantity of photosynthetic organs of the stems and poor mixing (Al-Saidi et al., 2009). Mixing near the soil surface was impeded by a locally-stable temperature stratification, which prevailed during the day below the barley canopy (Fig. 8f, g, j). The highest temperatures appeared near the canopy top two hours after solar noon (Fig. 7a). An individual profile near this time (Fig. 8f) demonstrates that similarly high temperatures prevailed throughout most of the canopy. Between 1400 and 1630 UTC, however, the temperature reached a distinct maximum just 

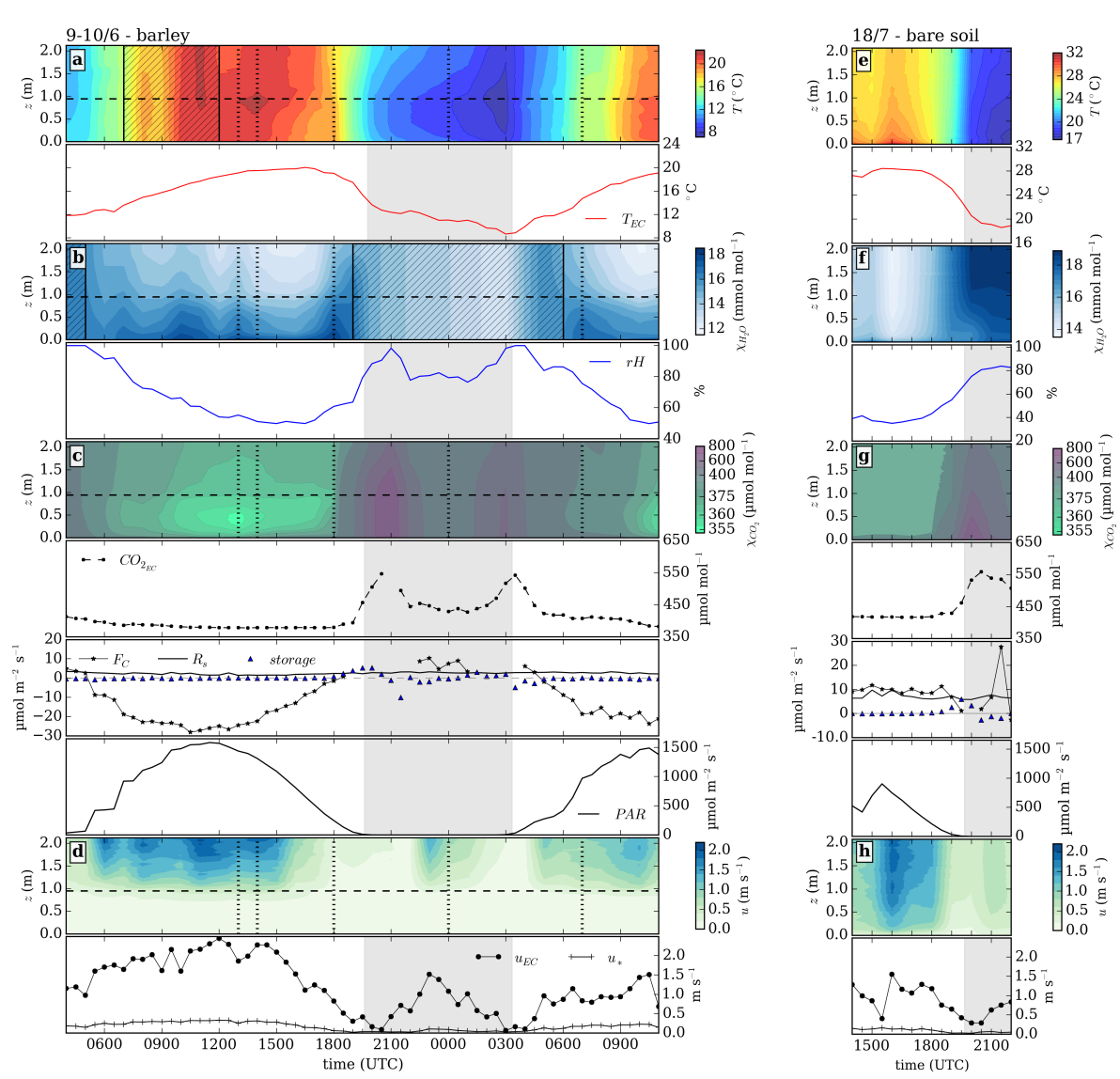

Fig. 7 Time-height sections and time series measured in a barley field (left) and bare soil (right). a) temperature $T$ and $T_{E C}$, b) $\chi_{\mathrm{H}_{2} \mathrm{O}}$ and relative humidity $\left.(\mathrm{RH}), \mathrm{c}\right) \chi_{C \mathrm{C}_{2}}, \mathrm{CO}_{2}$ flux $F_{C}$ (not gap filled), $\mathrm{CO}_{2 \mathrm{EC}}$ and the soil respiration $R_{s}$, the photosynthetically active radiation $P A R$ and d) wind speed $u_{E C}$ and friction velocity $u_{*}$. The ordinate is the height $z$ (m,a.g.l.). Black dashed lines show the plant height $(0.95 \mathrm{~m})$. Time series of temperature $T_{E C}$, relative humidity $R H, F_{C}, \mathrm{CO}_{2}, u_{E C}$ and $u_{*}$ are measured at $2.5 \mathrm{~m}$ above ground from the nearby eddy-covariance station. Solar noon corresponds to approximately 1130 UTC. Hatched areas refer to questionable data due to failure of thermocouple ventilation $(T)$ and missing tube heating $\left(\chi_{\mathrm{H}_{2} \mathrm{O}}\right)$ and grey shaded areas mark the nighttime. Vertical dotted lines in the figure on the left side mark selected 30-min mean profiles showed in Fig. 8

below the canopy top (Fig. 7a and Fig. 8g), a phenomenon that could also be observed after sunrise in the next morning. We hypothesize that the solar incident angle had an influence on the shape of the within-canopy temperature profile. Around noon, solar radiation penetrated deeper into the canopy. A decreasing angle of incidence in the afternoon limited the heating to an area just below the canopy surface. The presence or absence of such a distinct temperature maximum increases thermal stability, and thus impedes the turbulent vertical exchange of sensible heat, below it. Therefore, it may be self-reinforcing to some degree. We assume that in such a dense canopy the sensible heat flux was largely determined by the canopy structure. Similarly, the effect of low solar elevation angles was 
discussed by Gryning et al. (2001) for a coniferous high-latitude forest. This effect can also be found in the vertical $\chi_{\mathrm{CO}_{2}}$ profiles: solar radiation at a low incident angle reached only the upper part of the plants, which is indicated in Fig. $7 \mathrm{c}$ and Fig. $8 \mathrm{c}$ at 1800 UTC by a $\chi_{\mathrm{CO}_{2}}$ minimum just below the canopy surface, while the concentration in the deeper area already increased.

The vertical wind profile showed consistently low wind speeds within the canopy $\left(<0.8 \mathrm{~m} \mathrm{~s}^{-1}\right)$ throughout the observation period. Above the canopy layer and bare soil, the wind speed increased in a logarithmic-like profile.

In the late afternoon, cooling expanded upwards from the soil surface and continued in the night with the cooling surface shifted from the soil surface towards the canopy top. At this time, the soil surface was the warmest location within the canopy (Fig. 8i). Consequently the sign of stability differed between the canopy and the air above, which confirms results in Maitani and Seo (1986) and Jacobs et al. (1994). The lowest temperatures occurred in a wide region above and below the canopy top layer just before dawn at 0300 UTC. Over bare soil, the temperature profiles showed the expected logarithmic form with maximum values in the daytime, and minimum values in the nighttime near the soil surface. Isothermal conditions were crossed around one hour before sunset, with the sign change of net radiation (not shown here).

During the night, in particular in cases of calm conditions and low turbulence ( $u_{*}$ near zero), a large amount of $\mathrm{CO}_{2}\left(\chi_{\mathrm{CO}_{2}}\right.$ up to $\left.700 \mu \mathrm{mol} \mathrm{mol}^{-1}\right)$ accumulated over the whole profile height in barley (Fig. 7c) as well over bare soil (Fig. 7g). Matching high concentrations were also observed by the open-path instrument of the eddy-covariance station at $2.5 \mathrm{~m}$ above ground. We conclude that the high air humidity and the missing tube heating on 9-10 June did not affect the $\chi_{\mathrm{CO}_{2}}$ profile measurements to such a large extent as the $\chi_{\mathrm{H}_{2} \mathrm{O}}$ profile measurements.

At night during calm conditions, the wind-speed gradient was small over the whole profile (Fig. 7d, 2000 UTC an Fig. 8h) and the shape of the wind profile was approximately linear. Increasing wind speed led to a decrease of $\chi_{\mathrm{CO}_{2}}$ (Fig. 7c 2100 and 0300 UTC and Fig. 7g 2100 UTC). We found positive gradients of $\chi_{\mathrm{H}_{2} \mathrm{O}}$ above bare soil from $0.1 \mathrm{~m}$ upwards, possibly indicating dewfall. However, the gradients slightly increased towards the surface in the lowest $0.1 \mathrm{~m}$. Due to the rough and heterogeneous surface of the field mentioned above, as well as its heterogeneous surrounding (green sugar beet fields and tree rows vs. mature and harvested cereal fields), the sign of the latent heat flux may have varied in space.

The magnitude of the storage term (below Fig. $7 \mathrm{c}$ and g) was $<1 \mu \mathrm{mol} \mathrm{m}{ }^{-2}$ $\mathrm{s}^{-1}$ and $<1 \%$ of the eddy-covariance flux during daytime, but reached more than $10 \%$ of it and occasionally the same order of magnitude during evening, morning and part of the night. The events of ephemeral $\chi_{\mathrm{CO}_{2}}$ buildup during periods of low turbulence (two on 9-10 June and one on 18 July 2016) were each reflected by a large oscillation of consecutive positive and negative storage terms. For the largest storage terms, no reliable eddy-covariance fluxes are available for comparison, due to the effects of low friction velocities on quality control and of condensation on the open-path analyzer. 

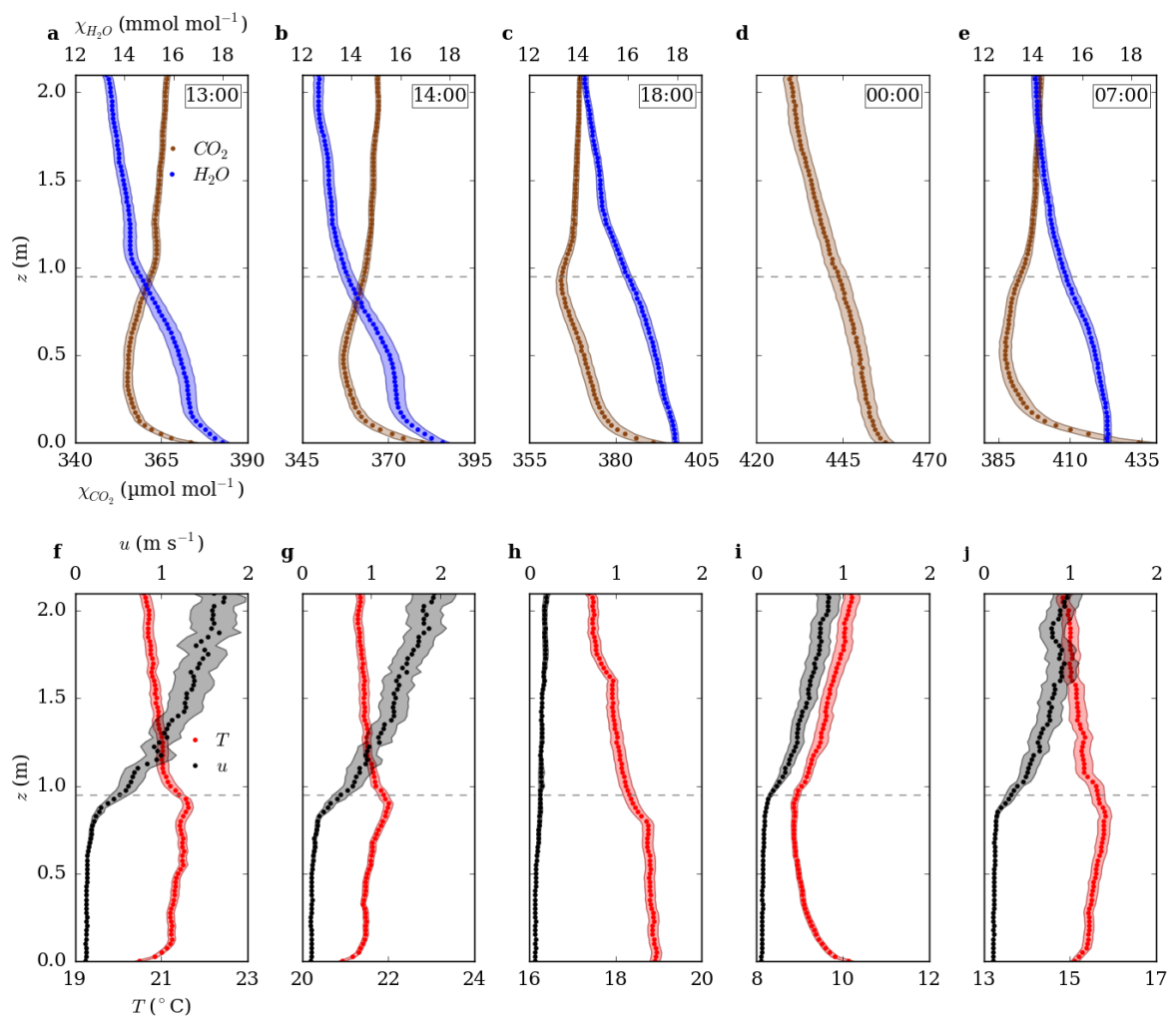

Fig. 8 Selected 30-min mean profiles of $\chi_{\mathrm{CO}_{2}}, \chi_{\mathrm{H}_{2} \mathrm{O}}$, wind speed $u$ and temperature $\mathrm{T}$ from Fig. 7. Time stamps declare the beginning of the 30 -min mean. Note the different absolute values in the units along the $x$-axis (scaling kept uniform).

\subsection{Comparison of profile-derived and eddy-covariance fluxes}

Figure 9 shows an example of theoretical profiles fitted according to Sect. 2.5 to 30 min mean profiles of potential temperature, wind speed, $\chi_{\mathrm{CO}_{2}}$ and $\chi_{\mathrm{H}_{2} \mathrm{O}}$, measured over bare soil. Lines show the modelled profiles after fitting $u_{*}, z_{0}$, scalar fluxes, scalar surface values at $z_{0 \theta}$ (assuming $z_{0 \theta}=0.1 z_{0}$ ) and the Obukhov length $L$, such that the root-mean-square difference between measured and modelled profile was minimal. The coefficient of determination for the profiles is higher than 0.94 for all four variables, which underlines that the measured profiles match well with MOST.

This was repeated for all measurements with a canopy height $\leq 0.22 \mathrm{~m}$, where the surface layer could be expected to cover a sufficiently large portion of the profile. Situations with a higher canopy are excluded here since the flux-gradient approach is only valid as long the eddy size is smaller than the transport scale, which is not always the case in real canopies (Denmead and Bradley, 1985). For each profile, $z_{0}$ and $d$ were estimated as described in Sect. 2.4. The resulting roughness length $z_{0}$ values were $0.01 \pm 0.004 \mathrm{~m}$ for bare soil and $0.06 \pm 0.01 \mathrm{~m}$ over the $0.22 \mathrm{~m}$ height catch-crop canopy, where the calculated $d$ was $0.15 \pm 0.03$ 

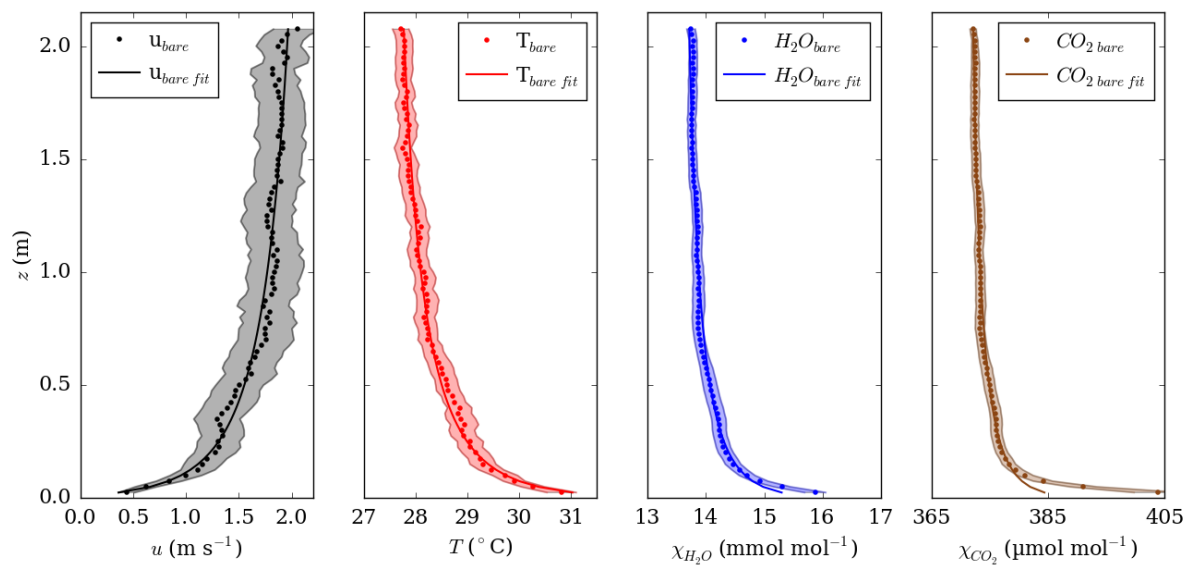

Fig. 9 Profiles on 18 July 20161600 UTC (bare) for wind speed $u$, potential temperature $\theta$, $\chi_{\mathrm{CO}_{2}}$ and $\chi_{\mathrm{H}_{2} \mathrm{O}}$ vs. height $z$ (m, a.g.l.). Lines indicate model profiles after fitting $u_{*}, z_{0}$, scalar fluxes, scalar surface values at $z_{0 \theta}$ (assuming $z_{0 \theta}=0.1 z_{0}$ ) and the Obukhov length $L$, such that the root-mean-square difference between measured and modelled profiles was minimal.

$\mathrm{m}$. The empirical algorithm removing data points from the bottom of the profile (see Sect. 2.4) omitted between none and three (corresponding to the lowermost $0.08 \mathrm{~m}$ ) data points over bare soil, but on average $0.4 \pm 0.13 \mathrm{~m}$ on the day with the highest canopy $(0.22 \mathrm{~m})$. This automatic deletion is in fair agreement with common assumptions on the height at which surface-layer scaling is approximately valid. For example, the rule $z>d+4\left(h_{c}-d\right)$ (Munger et al., 2012) yields 0.35 to 0.5 $\mathrm{m}$ with the above displacement heights and 0.44 with $d=2 / 3 h_{c}$, where $h_{c}$ is the canopy height.

The resulting fluxes of sensible and latent heat, $H_{P R}$ and $\lambda E_{P R}$ respectively, and $u_{* P R}$ were compared with those determined from the eddy-covariance approach (Fig. 10). The sample size is 15 for the heat fluxes, 14 for $F_{C}$ and 13 for $u_{*}$, depending on available reference data of the eddy-covariance station. The bivariate statistic in Tab. 3 indicates a good overall agreement, particularly for the latent heat flux and $F_{C}$ (both $R^{2}=0.91$ ). The bias was smallest, with less than $1 \%$ for $F_{C}$, and largest for $u_{*}\left(7.3 \%, R^{2}=0.73\right)$. The coefficients of determination and bias indicate that the profile measurement and raw-data processing approach are suitable to determine vertical profiles, in particular for $\chi_{\mathrm{CO}_{2}}$ and $\chi_{\mathrm{H}_{2} \mathrm{O}}$. During the potential dew night of 18 July 2016 discussed at the end of Sect. 3.3, the profile method yielded slightly negative latent heat fluxes between zero and -0.2 $\mathrm{W} \mathrm{m} \mathrm{m}^{-2}$, while the eddy-covariance station yielded one positive and three negative 30-min fluxes between $+9 \mathrm{~W} \mathrm{~m}^{-2}$ and $-4 \mathrm{~W} \mathrm{~m}^{-2}$. Such differences are well inside the uncertainty range of eddy-covariance measurements (Kessomkiat et al., 2013; Mauder et al., 2013). 

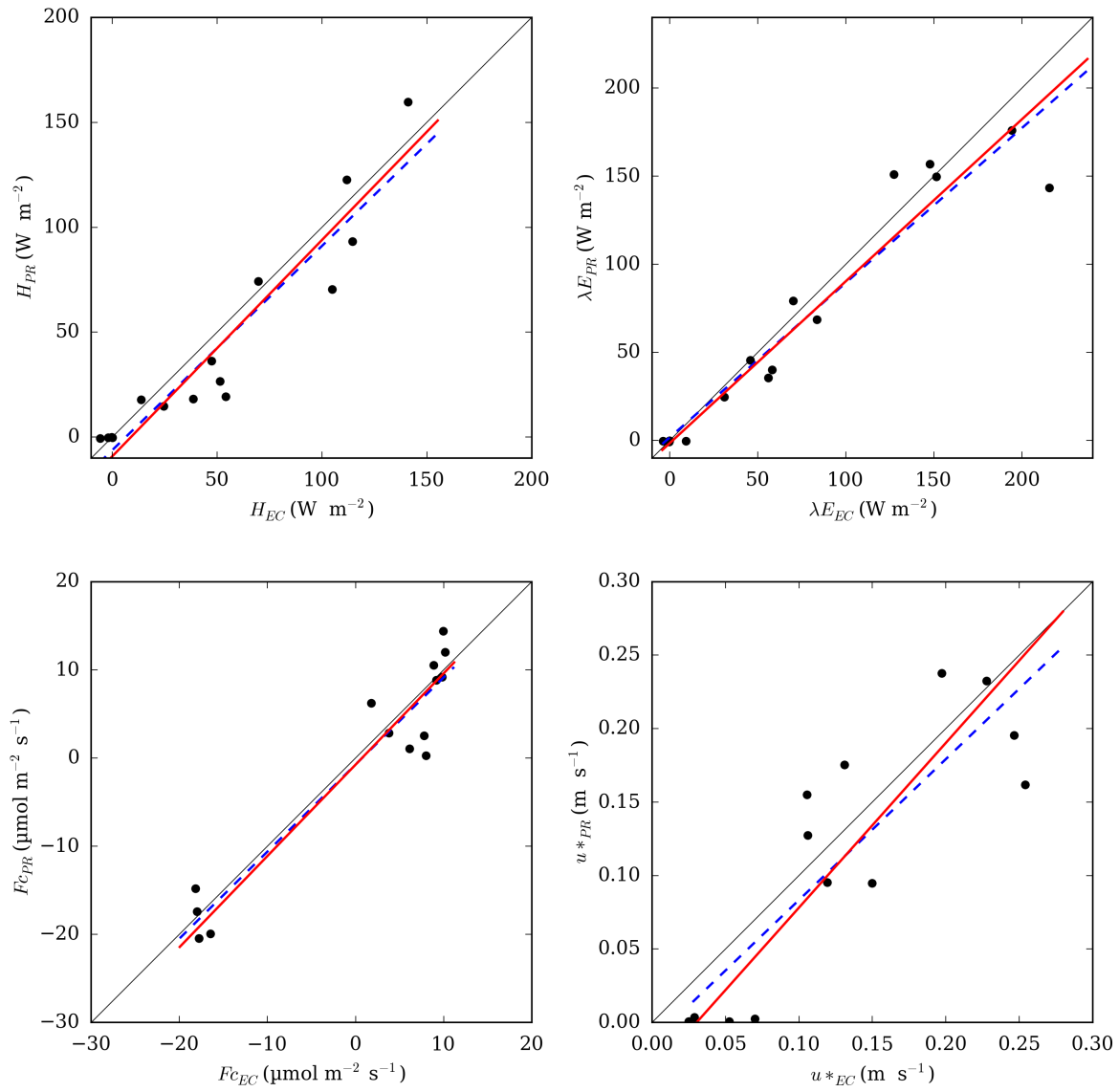

Fig. 10 Comparison of profile-derived measured profiles over bare soil (six data points) and low canopy height $(\leq 0.22 \mathrm{~m})$ (nine data points) vs. observed sensible heat flux $H$ and latent heat flux $\lambda E, F_{C}$ and $u_{*}$ from the eddy-covariance station. The solid black line is the 1:1 line, the red line is the reduced major axis (Webster, 1997) and the blue dashed lines are the least square regression line.

Table 3 Bi-variate statistics of the profile-derived vs. eddy-covariance dataset shown in Fig. $10, \mathrm{RMA}=$ reduced major axis.

\begin{tabular}{|c|c|c|c|c|}
\hline Quantity & Latent heat flux & $\mathrm{CO}_{2}$ flux & Sensible heat flux & $u_{*}$ \\
\hline Bias & $\begin{array}{c}7.9 \mathrm{~W} \mathrm{~m}^{-2} \\
(6.9 \%)\end{array}$ & $\begin{array}{c}0.7 \mu \mathrm{mol} \mathrm{m} \mathrm{m}^{-2} \mathrm{~s}^{-1} \\
(0.7 \%)\end{array}$ & $\begin{array}{c}7.8 \mathrm{~W} \mathrm{~m}^{-2} \\
(6.8 \%)\end{array}$ & $\begin{array}{c}0.02 \mathrm{~m} \mathrm{~s}^{-1} \\
(7.6 \%)\end{array}$ \\
\hline$R M S E$ & $22.3 \mathrm{~W} \mathrm{~m}^{-2}$ & $3.7 \mu \mathrm{mol} \mathrm{m} \mathrm{m}^{-2} \mathrm{~s}^{-1}$ & $17.7 \mathrm{~W} \mathrm{~m}^{-2}$ & $0.05 \mathrm{~m} \mathrm{~s}^{-1}$ \\
\hline$M A D$ & $8.8 \mathrm{~W} \mathrm{~m}^{-2}$ & $3.0 \mu \mathrm{mol} \mathrm{m} \mathrm{m}^{-2} \mathrm{~s}^{-1}$ & $10.6 \mathrm{~W} \mathrm{~m}^{-2}$ & $0.04 \mathrm{~m} \mathrm{~s}^{-1}$ \\
\hline$R^{2}$ & 0.91 & 0.91 & 0.89 & 0.73 \\
\hline RMA slope & 0.9 & 1.0 & 1.0 & 1.1 \\
\hline RMA offset & $1.7 \mathrm{~W} \mathrm{~m}^{-2}$ & $-0.7 \mu \mathrm{mol} \mathrm{m} \mathrm{m}^{-2} \mathrm{~s}^{-1}$ & $-6.5 \mathrm{~W} \mathrm{~m}^{-2}$ & $-0.01 \mathrm{~m} \mathrm{~s}^{-1}$ \\
\hline
\end{tabular}


Apart from evaluation against eddy-covariance measurements, fluxes from profiles can also be directly assessed in terms of energy balance closure. On a longterm basis, the eddy-covariance measurements at the site exhibited a closure of 0.85 (Eder et al., 2015). For the 30-min with profile-based estimates of both turbulent heat fluxes, however, the energy balance ratio (Wilson et al., 2002) was 1.07. This may in part be due to too high soil heat flux estimates obtained in unmanaged soil in July 2016 (see Sect. 2.2). Without this date, the ratio is 0.82 . The respective energy balance ratios of the profile-derived fluxes were 0.97 and 0.80 , respectively.

\section{Conclusion and Outlook}

We described a high-resolution profile measurement technique based on an elevator system to obtain vertical profiles of $\mathrm{CO}_{2}$ and $\mathrm{H}_{2} \mathrm{O}$ mole fractions, temperature and wind speed. Compared to most other existing systems, the elevator moves continuously. The resulting high vertical resolution may provide a more detailed insight into sources, sinks and processes within a short plant canopy than systems with a finite number of measurement heights.

Measurements during two years within and above crop canopies were largely consistent with profiles found in textbooks based on earlier finite-level measurements and assumptions (Waterhouse, 1955; Kaimal and Finnigan, 1994; Monteith and Unsworth, 2013), but revealed several interesting details concerning the location of scalar minima and maxima within the canopy and close to the surface, and their evolution during the day.

We tested the validity of the measurements by comparing fluxes derived during situations with a single sink or source at or near the soil surface to those determined with a nearby eddy-covariance station. Results were promising particularly for $\mathrm{CO}_{2}$ and $\mathrm{H}_{2} \mathrm{O}$. This suggests that the profiles determined in canopies with vertically displaced sources can be used in future studies for other tasks, such as validating soil-vegetation-atmosphere models that depend on accurate estimates of $\mathrm{CO}_{2}$ and $\mathrm{H}_{2} \mathrm{O}$ concentrations near the stomata. Inverting concentration profiles within the canopy has been suggested as a way of inferring the vertical scalar source and sink processes. Previous attempts with Lagrangian dispersion analysis used a limited number of measurement heights and were mostly performed in high canopies such as maize and forest (Raupach, 1989; Leuning, 2000; Santos et al., 2011). The use of concentrations with high vertical resolution may improve their applicability and robustness especially in low, dense canopies.

Since source attribution is of interest in tall canopies like forests as well, and other motivations for profile measurements, such as computing storage terms, are of particular interest in such ecosystems, it is interesting to note the limitations of the current design when varying the profile height. Apart from required technical adaptations, the current elevator speed would result in a low number of repetitions per averaging time, with unwanted effects on the profile uncertainty. The discussion of the effects of a synthetically reduced raw data acquisition frequency in Sect. 3.1 indicated that a large number of repetitions is crucial, while consecutive repetitions during a single pass of a target height bin add little to uncertainty reduction. This means that the elevator speed can be increased, as long as it is matched by the physical response time of the sensors. For $\mathrm{CO}_{2}$ and $\mathrm{H}_{2} \mathrm{O}$, this would require 
either a stronger pump or an open-path analyzer. It should be noted, however, that the same measures might be counterproductive for short, dense canopies, in which it is more important than in forests to keep the sensor size and sample air volume small. Also, in forests, a lower vertical resolution (larger height bin size) can be afforded, further increasing the possible elevator speed. In general a system of the type described here should strive to retain a high number of soundings $M_{1}$ by adjusting the parameters in $M_{1}=t v / h$ while satisfying the condition $\min \left(f_{1}, f_{2}\right) \geq v / \Delta h$, where $t$ is the target averaging time block length, $v$ is the elevator speed, $h$ is the profile height, $\Delta h$ is the height bin size, $f_{1}$ is the raw data acquisition frequency and $f_{2}$ is the response frequency of the sensors including effects such as tube damping. If the motivation of performing profile measurements is unavailability of eddy-covariance type fast response sensors for the variable of interest, these two frequencies can limit applicability of the system to tall profiles; otherwise more technical limitations to $v$ such as security issues or avoiding additional turbulence creation will become determining. For a profile of $40 \mathrm{~m}$ height range, 60 -min averaging and $0.33-\mathrm{m}$ vertical resolution, however, an elevator speed of $0.33 \mathrm{~m} \mathrm{~s}^{-1}$ and frequencies $\geq 1 \mathrm{~s}^{-1}$ would still be sufficient.

Acknowledgements This study was financed by the German Federal Ministry of Education and Research (BMBF) in the framework of the project "IDAS-GHG" (FKZ 01LN1313A). Ancillary hardware and its maintenance was supported by TERENO and the DFG Collaborative Research Centre 32 "Patterns in Soil-Vegetation-Atmsophere Systems". We gratefully thank Normen Hermes for developing the control electronics for the elevator system, Yannick Tolsdorf for assistance with it, Nicole Adels, Odilia Esser, Daniel Dolfus and Marius Schmidt for conducting most of the eddy covariance, chamber and PAI fieldwork and analyses and four anonymous reviewers for thorough screening of and constructive comments on the manuscript.

\section{Appendix 1}

In 2015, the soil heat flux, temperature and moisture measurements (Sect. 2.2) were performed in a single location near the eddy-covariance station in representatively managed soil. In July 2016, this array was uninstalled due to cultivation, but installation of an ICOS-compliant (Op de Beeck et al., 2015) distributed array of five such locations was started. Until after repeated cultivation and seeding (September 2016), however, only the emergency plot of this array, directly next to the eddy-covariance station on unmanaged soil, was available. Heat flux plates were installed at a depth of $0.08 \mathrm{~m}$ in the pre-ICOS set-up and of $0.05 \mathrm{~m}$ in the ICOS-compliant set-up.

The two sampling tubes for the moving and the fixed $\chi_{\mathrm{CO}_{2}}$ and $\chi_{\mathrm{H}_{2} \mathrm{O}}$ measurements (Sect. 2.3) are of the same length to assure identical time lags. However, this length was changed from $3 \mathrm{~m}$ to $4.5 \mathrm{~m}$ before 31 May 2016 to allow for a longer conduit for large canopy heights and a larger tolerance radius for setting up the analyzer. The extension ensured that the tube end dipped into the plant canopy at a horizontal distance of $0.3 \mathrm{~m}$ from all other installations and $1.1 \mathrm{~m}$ below the carriage, preventing the carriage itself from dipping into the canopy, and thus minimizing mechanical stress.

In 2016, the tubes were equipped with an optional heating system to prevent condensation of moist air on the inner surface of the tubing, particularly during nighttime conditions, with a $2.5-\mathrm{m}$ long heating wire (bed heater for aquarium, 
and

Eco-Line ThermoTronic 5 Watt, Dennerle GmbH, Germany) wrapped helically around the first $1.2 \mathrm{~m}$ of both inlets tubes, insulated over the entire length of the tube by insulating hoses with an insulation thickness of $0.013 \mathrm{~m}$, and covered by self-adhesive aluminum tape.

The signals of the wind sensors were logged on the same file as the gas concentrations via the auxiliary ports of the LI7000. The thermocouple temperatures were logged at intervals of $0.05 s$ to a logger (CR1000, Campbell Scientific, Inc., Logan, Utah, USA).

The final wind and temperature set-up, used in 2016, was the result of stepwise improvements to a preliminary set-up during 2015. Initially no fixed-height anemometer existed, and the moving thermocouple was operated in the open and without ventilation, shielded only by a wire mesh, which however failed to secure the delicate thermocouple junction for more than a few hours. As a result, temperature measurements during the first year are partly missing and were partly performed with an improvised repair, where the more rugged compensation lines of the thermocouple were directly connected to each other. These temperature data, however, were not used. Profiles of $\chi_{\mathrm{CO}_{2}}$ and $\chi_{\mathrm{H}_{2} \mathrm{O}}$ are used during this time because they are not affected by missing temperature measurements. The most important changes to the set-up are indicated in Table 1.

\section{Appendix 2}

Flux derivation from surface-layer profiles is based on the integrated flux-profile relations for momentum, heat and mass:

$$
\begin{aligned}
& \frac{u}{u_{*}}=\frac{1}{\kappa}\left[\ln \frac{z-d}{z_{0}}-\psi_{m}\left(\frac{z-d}{L}\right)\right], \\
& \frac{\theta-\theta_{0}}{\theta_{*}}=\frac{1}{\kappa}\left[\ln \frac{z}{z_{0 \theta}}-\psi_{h}\left(\frac{z-d}{L}\right)\right],
\end{aligned}
$$

$$
\frac{X-X_{0}}{X *}=\frac{1}{\kappa}\left[\ln \frac{z}{z_{0 \theta}}-\psi_{h}\left(\frac{z-d}{L}\right)\right],
$$

where $u_{*}$ is the friction velocity, $\kappa=0.4$ is the von Karman constant, $z_{0}$ and $d$ are the aerodynamic roughness length and displacement height, $z_{0 \theta}$ is the scalar roughness length, and $L$ is the Obukhov length,

$$
L=-\frac{u_{*}^{3}}{\kappa \frac{g}{\theta} \frac{H}{\rho_{a i r} c_{p}}},
$$

with the acceleration due to gravity $g ; \theta$ is potential temperature, $H$ is the sensible heat flux, $\rho_{a i r}$ is the density of air and $c_{p}$ is the specific heat at constant pressure. Potential temperature was computed by applying an adiabatic lapse rate, based on the 30-min mean temperature and pressure, such that the 2-m-a.s.l. level served as a reference. The largest deviations from air temperature, occurring thus at the surface, were $0.02{ }^{\circ} \mathrm{C}$, and the effects on computed fluxes were $\leq 0.2 \mathrm{~W} \mathrm{~m}^{-2} \cdot \theta_{0}$ and $X_{0}$ are the potential temperature or the fractional concentration by mass of 
the scalar $X$ at $z-d=z_{0 \theta}$; and $\theta_{*}$ and $X_{*}$ are the scaling parameters for the temperature and a concentration $X$, expressed by

$$
\begin{gathered}
\theta_{*}=\frac{-H}{c_{p} \rho u_{*}}, \\
X_{*}=\frac{-F_{X}}{\rho u_{*}} .
\end{gathered}
$$

The stability corrections required in Eq. 9 and 10 (integrated form universal functions) for momentum exchange $\psi_{m}$ and the exchange of sensible heat $\psi_{h}$ after Businger et al. (1971) are used in the modified version after Högström (1988). The universal function for the exchange of sensible heat $\psi_{h}$ is also used in the profile equation 11 for the calculation of moisture exchange and for the exchange of trace gases like $\mathrm{CO}_{2}$ (Panofsky and Dutton, 1984).

\section{References}

Ahonen T, Aalto P, Rannik Ü, Kulmala M, Nilsson ED, Palmroth S, Ylitalo H, Hari P (1997) Variations and vertical profiles of trace gas and aerosol concentrations and $\mathrm{CO}_{2}$ exchange in eastern lapland. Atmos Env 31:3351-3362

Al-Saidi A, Fukuzawa Y, Furukawa N, Ueno M, Baba S, Kawamitsu Y (2009) A system for the measurement of vertical gradients of $\mathrm{CO}_{2}, \mathrm{H}_{2} \mathrm{O}$ and air temperature within and above the canopy of plant. Plant Prod Sci 12:139-149

Arya PS (2001) Introduction to micrometeorology. Academic Press, San Diego, $420 \mathrm{pp}$

Aubinet M, Berbigier P, Bernhofer C, Cescatti A, Feigenwinter C, Granier A, Gruenwald T, Havrankova K, Heinesch B, Longdoz B, et al. (2005) Comparing $\mathrm{CO}_{2}$ storage and advection conditions at night at different carboeuroflux sites. Boundary-Layer Meteorol 116:63-93

Baghi R, Durand P, Jambert C, Jarnot C, Delon C, Serça D, Striebig N, Ferlicoq M, Keravec P (2012) A new disjunct eddy-covariance system for bvoc flux measurements-validation on co2 and h2o fluxes. Atmos Meas Tech 5:3119-3132

Op de Beeck M, Gielen B, Merboldt L, co authors (2015) Icos protocol soilmeteorological variables, final version v3. Internal report, ICOS Ecosystem Thematic Centre, $48 \mathrm{pp}$

Billesbach DP (2011) Estimating uncertainties in individual eddy covariance flux measurements: a comparison of methods and a proposed new method. Agric For Meteorol 151:394-405

Bloom AJ, Mooney HA, Björkman O, Berry J (1980) Materials and methods for carbon dioxide and water exchange analysis. Plant, Cell \& Environment 3:371376

Brooks JR, Flanagan LB, Varney GT, Ehleringer JR (1997) Vertical gradients in photosynthetic gas exchange characteristics and refixation of respired $\mathrm{CO}_{2}$ within boreal forest canopies. Tree Physiol 17:1-12

Buchmann N, Ehleringer JR (1998) $\mathrm{CO}_{2}$ concentration profiles, and carbon and oxygen isotopes in $\mathrm{C}_{3}$ and $\mathrm{C}_{4}$ crop canopies. Agric and For Meteorol 89:45-58

Businger JA, Oncley SP (1990) Flux measurement with conditional sampling. J Atmos Oceanic Tech 7:349-352 
Businger JA, Wyngaard JC, I Y, Bradley EF (1971) Flux-profile relationships in the atmospheric surface layer. J Atmos Sci 28:181-189

Denmead OT, Bradley EF (1985) Flux-gradient relationships in a forest canopy. In: The forest-atmosphere interaction, Springer, pp 421-442

Deutscher-Wetterdienst (2016) Klimadaten für Messstationen in Deutschland. URL http://www.dwd.de/DE/leistungen/klimadatendeutschland/ klimadatendeut schl and.html, (06.07.2016)

Drüe C (1996) Aufbau einer Profil-Messstation im Pflanzenbestand. Master's thesis, Meteorologisches Institut Universität Bonn, Auf dem Hügel 20, 53121 Bonn, Germany

Eder F, Schmidt M, Damian T, Träumner K, Mauder M (2015) Mesoscale eddies affect near-surface turbulent exchange: evidence from lidar and tower measurements. J Appl Meteorol Clim 54:189-206

Euser T, Luxemburg W, Everson C, Mengistu M, Clulow A, Bastiaanssen W (2014) A new method to measure bowen ratios using high-resolution vertical dry and wet bulb temperature profiles. Hydrol and Earth Syst Sci 18:2021-2032

Finkelstein PL, Sims PF (2001) Sampling error in eddy correlation flux measurements. J Geophysl Res Atmos 106:3503-3509

Foken T (2006) Angewandte Meteorologie. Mikrometeorologische Methoden, 2nd edn. Springer, Berlin, $344 \mathrm{pp}$

Fotiadi AK, Lohou F, Druilhet A, Serça D, Brunet Y, Delmas R (2005a) Methodological development of the conditional sampling method. part i: Sensitivity to statistical and technical characteristics. Boundary-Layer Meteorol 114(3):615640

Fotiadi AK, Lohou F, Druilhet A, Serça D, Said F, Laville P, Brut A (2005b) Methodological development of the conditional sampling method. part ii: Quality control criteria of relaxed eddy accumulation flux measurements. BoundaryLayer Meteorol 117(3):577-603

Graf A, Weihermüller L, Huisman JA, Herbst M, Bauer J, Vereecken H (2008) Measurement depth effects on the apparent temperature sensitivity of soil respiration in field studies. Biogeosciences 5:1175-1188

Graf A, Schüttemeyer D, Geiß H, Knaps A, Möllmann-Coers M, Schween JH, Kollet S, Neininger B, Herbst M, Vereecken H (2010) Boundedness of turbulent temperature probability distributions, and their relation to the vertical profile in the convective boundary layer. Boundary-Layer Meteorol 134(3):459-486

Graf A, Herbst M, Weihermüller L, Huisman JA, Prolingheuer N, Bornemann L, Vereecken H (2012) Analyzing spatiotemporal variability of heterotrophic soil respiration at the field scale using orthogonal functions. Geoderma 181:91-101

Gryning SE, Batchvarova E, De Bruin HAR (2001) Energy balance of a sparse coniferous high-latitude forest under winter conditions. Boundary-Layer Meteorol 99:465-488

Haverd V, Cuntz M, Griffith D, Keitel C, Tadros C, Twining J (2011) Measured deuterium in water vapour concentration does not improve the constraint on the partitioning of evapotranspiration in a tall forest canopy, as estimated using a soil vegetation atmosphere transfer model. Agric For Meteorol 151:645-654

Högström U (1988) Non-dimensional wind and temperature profiles in the atmospheric surface layer: A re-evaluation. Boundary-Layer Meteorol 42:55-78

Ibrom A, Dellwik E, Flyvbjerg H, Jensen NO, Pilegaard K (2007) Strong lowpass filtering effects on water vapour flux measurements with closed-path eddy 
correlation systems. Agric For Meteorol 147:140-156

Jacobs A, Van Boxel J, El-Kilani R (1994) Nighttime free convection characteristics within a plant canopy. Boundary-Layer Meteorol 71:375-391

Jäggi M, Ammann C, Neftel A, Fuhrer J (2006) Environmental control of profiles of ozone concentration in a grassland canopy. Atmos Env 40:5496-5507

Kaimal JC, Finnigan JJ (1994) Atmospheric boundary layer flows: their structure and measurement. Oxford University Press, New York, 289 pp

Kessomkiat W, Franssen HJH, Graf A, Vereecken H (2013) Estimating random errors of eddy covariance data: An extended two-tower approach. Agric For Meteorol 171:203-219

Lenschow DH, Mann J, Kristensen L (1994) How long is long enough when measuring fluxes and other turbulence statistics? J Atmos Ocean Technol 11:661-673

Leuning R (2000) Estimation of scalar source/sink distributions in plant canopies using lagrangian dispersion analysis: corrections for atmospheric stability and comparison with a multilayer canopy model. Boundary Layer Meteorol 96:293314

Lothon M, Lohou F, Pino D, Couvreux F, Pardyjak E, Reuder J, Vilà-Guerau De Arellano J, Durand P, Hartogensis O, Legain D, et al. (2014) The BLLAST field experiment: Boundary-layer late afternoon and sunset turbulence. Atmos Chem Phys 14:10931-10960

Maitani T, Seo T (1986) A case study of temperature fluctuations within and above a wheat field before and after sunset. Boundary-Layer Meteorol 35:247-256

Mammarella I, Launiainen S, Gronholm T, Keronen P, Pumpanen J, Rannik Ü, Vesala T (2009) Relative humidity effect on the high-frequency attenuation of water vapor flux measured by a closed-path eddy covariance system. J Atmos and Ocean Tech 26:1856-1866

Mauder M, Foken T (2011) Documentation and instruction manual of the eddycovariance software package TK3, vol 46. University of Bayreuth, Department of Micrometeorology

Mauder M, Cuntz M, Drüe C, Graf A, Rebmann C, Schmid HP, Schmidt M, Steinbrecher R (2013) A strategy for quality and uncertainty assessment of long-term eddy-covariance measurements. Agric For Meteorol 169:122-135

Mayer JC, Hens K, Rummel U, Meixner FX, Foken T (2009) Moving measurement platforms-specific challenges and corrections. Meteorol Z 18(5):477-488

Mayer JC, Bargsten A, Rummel U, Meixner FX, Foken T (2011) Distributed modified bowen ratio method for surface layer fluxes of reactive and non-reactive trace gases. Agric For Meteorol 151(6):655-668

Miyata A, Leuning R, Denmead OT, Kim J, Harazono Y (2000) Carbon dioxide and methane fluxes from an intermittently flooded paddy field. Agric For Meteorol 102:287-303

Moene AF, Michels BI (2002) Estimation of the statistical error in large eddy simulation results. American Meteorological Society, Wageningen, the Netherlands Boston, U.S.A., pp 287-288

Montagnani L, Manca G, Canepa E, Georgieva E, Acosta M, Feigenwinter C, Janous D, Kerschbaumer G, Lindroth A, Minach L, Minerbi S, Mölder M, Pavelka M, Seufert G, Zeri M, Ziegler W (2009) A new mass conservation approach to the study of $\mathrm{CO}_{2}$ advection in an alpine forest. J Geophys Res Atmos 114(D7) 
Monteith J, Unsworth M (2013) Principles of environmental physics: plants, animals, and the atmosphere, 4th edn. Elsevier, Ltd., $423 \mathrm{pp}$

Munger JW, Loescher HW, Luo H (2012) Measurement, tower, and site design considerations. In: Eddy Covariance, Springer, pp 21-58

Noone D, Risi C, Bailey A, Berkelhammer M, Brown D, Buenning N, Gregory S, Nusbaumer J, Schneider D, Sykes J, Vanderwende B, Wong J, Meillier Y, Wolfe D (2013) Determining water sources in the boundary layer from tall tower profiles of water vapor and surface water isotope ratios after a snowstorm in colorado. Atmos Chem and Phys 13:1607-1623

Nordbo A, Kekäläinen P, Siivola E, Lehto R, Vesala T, Timonen J (2013) Tube transport of water vapor with condensation and desorption. Applied Physics Letters 102:194101

Panofsky HA, Dutton JA (1984) Atmospheric turbulence. Models and methods for engineering applications. John Wiley \& Sons, Inc., New York, 397 pp

Raupach MR (1989) A practical lagrangian method for relating scalar concentrations to source distributions in vegetation canopies. Q J R Meteorol Soc 115:609-632

Reichstein M, Falge E, Baldocchi D, Papale D, Aubinet M, Berbigier P, Bernhofer C, Buchmann N, Gilmanov T, Granier A, Gruenwald T, Havrankova K, Janous D, Knohl A, Laurela T, Lohila A, Loustau D, Matteucci G, Meyers T, Miglietta F, Ourcival JM, Rambal S, Rotenberg E, Sanz M, Tenhunen J, Seufert G, Vaccari F, Vesala T, Yakir D (2005) On the separation of net ecosystem exchange into assimilation and ecosystem respiration: Review and improved algorithm. Glob Change Biol 11:1424-1439

Rinne HJI, Guenther AB, Warneke C, De Gouw JA, Luxembourg SL (2001) Disjunct eddy covariance technique for trace gas flux measurements. Geophys Res Lett 28(16)

Santos EA, Wagner-Riddle C, Warland JS, Brown S (2011) Applying a lagrangian dispersion analysis to infer carbon dioxide and latent heat fluxes in a corn canopy. Agric For Meteorol 151:620-632

Sogachev A, Leclerc M, Karipot A, Zhang G, Vesala T (2005) Effect of clearcuts on footprints and flux measurements above a forest canopy. Agric For Meteorol $133: 182-196$

Thomas CK, Kennedy AM, Selker JS, Moretti A, Schroth MH, Smoot AR, Tufillaro NB, Zeeman MJ (2012) High-resolution fibre-optic temperature sensing: A new tool to study the two-dimensional structure of atmospheric surface-layer flow. Boundary-Layer Meteorol 142:177-192

Van Dijk A, Moene AF, De Bruin HAR (2004) The principles of surface flux physics: theory, practice and description of the ecpack library. Meteorology and Air Quality Group, Wageningen University, Wageningen, The Netherlands p 99 pp

Waterhouse F (1955) Microclimatological profiles in grass cover in relation to biological problems. Q J R Meteorol Soc 81:63-71

Webster R (1997) Regression and functional relations. European Journal of Soil Science 48:557-566

Wilson K, Goldstein A, Falge E, Aubinet M, Baldocchi D, Berbigier P, Bernhofer C, Ceulemans R, Dolman H, Field C, Grelle A, Ibrom A, Law B, Kowalski T A and; Meyers, Moncrieff J, Monson W Rand Oechel, Tenhunen J, Verma S, Valentini R (2002) Energy balance closure at fluxnet sites. Agric For Meteorol 
$853 \quad 113: 223-243$

${ }_{854} \mathrm{Xu}$ L, Matista AA, Hsiao TC (1999) A technique for measuring $\mathrm{CO}_{2}$ and water ${ }_{855}$ vapor profiles within and above plant canopies over short periods. Agric For ${ }_{856}$ Meteorol 94:1-12 